\title{
Modalities and Mechanisms of Treatment for Coronavirus Disease 2019
}

\begin{abstract}
Zhihong Zuo ${ }^{1,2 \dagger}$, Ting $\mathrm{Wu}^{1,3+}$, Liangyu Pan ${ }^{1}$, Chenzhe Zuo ${ }^{1,2}$, Yingchuo $\mathrm{Hu}^{1}$, Xuan Luo ${ }^{4}$, Liping Jiang ${ }^{2}$, Zanxian Xia ${ }^{5,6}$, Xiaojuan Xiao ${ }^{1}$, Jing Liu ${ }^{1}$, Mao $\mathrm{Ye}^{7}$ and Meichun Deng ${ }^{1,2,6 *}$

${ }^{1}$ Department of Biochemistry and Molecular Biology and Hunan Province Key Laboratory of Basic and Applied Hematology, School of Life Sciences, Central South University, Changsha, China, ${ }^{2} X i a n g y a$ School of Medicine, Central South University, Changsha, China, ${ }^{3}$ Department of Cardiovascular Medicine, The Third Xiangya Hospital, Central South University, Changsha, China, ${ }^{4}$ Hunan Yuanpin Cell Biotechnology Co., Ltd., Changsha, China, ${ }^{5}$ Department of Cell Biology, School of Life Sciences, Central South University, Changsha, China, ${ }^{6}$ Hunan Key Laboratory of Animal Models for Human Diseases, Hunan Key Laboratory of Medical Genetics and Center for Medical Genetics, School of Life Sciences, Central South University, Changsha, China, ${ }^{7}$ Molecular Science and Biomedicine Laboratory, State Key Laboratory for Chemo/Biosensing and Chemometrics, College of Biology, College of Chemistry and Chemical Engineering, Collaborative Innovation Center for Molecular Engineering for Theranostics, Hunan University, Changsha, China
\end{abstract}

OPEN ACCESS

Edited by:

Rafael Maldonado,

Pompeu Fabra University, Spain

Reviewed by:

Amer Hayat Khan,

Universiti Sains Malaysia (USM), Malaysia

Dermot Cox

Royal College of Surgeons in Ireland,

Ireland

*Correspondence:

Meichun Deng

dengmch@csu.edu.cn

${ }^{+}$These authors have contributed equally to this work

Specialty section: This article was submitted to Pharmaceutical Medicine and Outcomes Research,

a section of the journal

Frontiers in Pharmacology

Received: 17 September 2020 Accepted: 03 December 2020 Published: 08 February 2021

Citation: Zuo Z, Wu T, Pan L, Zuo C, Hu Y, Luo X, Jiang L, Xia Z, Xiao X, Liu J, Ye $M$ and Deng M (2021) Modalities and Mechanisms of Treatment for

Coronavirus Disease 2019.

Front. Pharmacol. 11:583914. doi: 10.3389/fphar.2020.583914
Coronavirus disease 2019 (COVID-19), which is caused by severe acute respiratory syndrome coronavirus 2 (SARS-CoV-2), is spreading rapidly throughout the world. Although COVID-19 has a relatively low case severity rate compared to SARS and Middle East Respiratory syndrome it is a major public concern because of its rapid spread and devastating impact on the global economy. Scientists and clinicians are urgently trying to identify drugs to combat the virus with hundreds of clinical trials underway. Current treatments could be divided into two major part: anti-viral agents and host system modulatory agents. On one hand, anti-viral agents focus on virus infection process. Umifenovir blocks virus recognizing host and entry. Remdesivir inhibits virus replication. Chloroquine and hydroxychloroquine involve preventing the whole infection process, including virus transcription and release. On the other hand, host system modulatory agents are associated with regulating the imbalanced inflammatory reaction and biased immune system. Corticosteroid is believed to be commonly used for repressing hyper-inflammation, which is one of the major pathologic mechanisms of COVID-19. Convalescent plasma and neutralizing antibodies provide essential elements for host immune system and create passive immunization. Thrombotic events are at high incidence in COVID-19 patients, thus anti-platelet and anti-coagulation are crucial, as well. Here, we summarized these current or reproposed agents to better understand the mechanisms of agents and give an update of present research situation.

Keywords: SARS-CoV-2, COVID-19, mechanisms, treatment, therapeutic agents

\section{INTRODUCTION}

The coronavirus disease 2019 (COVID-19) pandemic, which is caused by the severe acute respiratory syndrome coronavirus 2 (SARS-CoV-2), has now affected 210 countries and territories, with more than five million confirmed cases. COVID-19 is rapidly spreading around the world, leading to widespread public concern and a global response. SARS-CoV-2, along with severe acute respiratory 
syndrome coronavirus (SARS-CoV) and Middle East respiratory syndrome coronavirus (MERS-CoV), belong to the betacoronavirus family. The full-length genome sequence of SARS-CoV-2 is $79.5 \%$ similar to MERS-CoV and $50 \%$ similar to SARS-CoV (Zhou P et al., 2020). Although we have learned much about the etiology and molecular characteristics of SARS-CoV-2, the origin of this novel virus remains unclear. Many studies support the hypothesis that bats are the most likely original host, with other animals, such as snakes or minks, acting as intermediate hosts (Li et al., 2005; Guo et al., 2020; Ji et al., 2020). SARS-CoV-2 targets the respiratory tract, but the lack of specific early symptoms makes it difficult to distinguish COVID-19 from other respiratory infections. Fever, cough, fatigue, and dyspnea are the most common early symptoms of COVID-19 (Booth et al., 2003; Yang J et al., 2020). In European patients, olfactory and gustatory dysfunction may precede the onset of respiratory symptoms and can be significant (Lechien et al., 2020). Patients with severe COVID-19 are vulnerable to complications and multi-organ damage (Huang C et al., 2020; $\mathrm{Wu} \mathrm{T}$ et al., 2020). Compared with SARS and MERS, COVID-19 has a lower case-fatality, but the virus has a higher basic reproduction number and higher transmissibility (Chan et al., 2003; Zumla et al., 2015). SARS-CoV-2 can be spread within communities, households, and hospitals by confirmed COVID19 patients or by asymptomatic individuals (Zhang X et al., 2020). The predominant transmission routes are droplet transmission and close contact, although other transmission routes such as erosol and fecal-oral transmission are possible, but not confirmed or refuted. It has been suggested that each patient with COVID-19 infects approximately 2.2 close contacts (Li Q et al., 2020), which partially accounts for the global COVID-19 pandemic.

Although some potential strategies for preventing the infection are proposed (Kang et al., 2020), however, in the absence of an effective vaccine, identification of effective drugs is crucial to treatment of this novel coronavirus. Both clinical experience and exploratory studies with other coronaviruses suggest more than 20 agents that may be potentially used to treat COVID-19. Some of these drugs such as corticosteroids, Chloroquine and Hydroxychloroquine (CQ/HCQ), as well as Lopinavir and Ritonavir (LPV/r) have been widely used in clinical practice, whereas others, such as Janus Kinase (JAK) inhibitors, have been introduced only recently. In this review, we have compiled all available evidence with which to establish a framework for COVID-19 treatment as well as therapeutic optimization.

\section{MECHANISMS OF VIRUS INFECTION}

Recognition: SARS-CoV-2 is a positive-stranded ribonucleic acid $(+\mathrm{RNA})$ virus, whose genes encode 16 nonstructural proteins (nsp1 to nsp16) and four structural proteins, including Membrane (M), Spike(S), Envelope (E) and Nucleocapsid (N). Among them, $\mathrm{S}$ protein makes contribution to homo-trimeric spikes which are responsible for the virus entry via recognizing with the host receptor angiotensin converting enzyme II (ACE2) (Chen Y et al., 2020). S proteins can be cleaved into by an appropriate protease into two functional domains (S1 and S2) (Hoffmann et al., 2020). The receptor-binding domain (RBD) within S1 subunit is a key functional component for binding with ACE2 (Lan et al., 2020). In addition, S1 can be further divided into a C-terminal domain (CTD) and N-terminal domain (NTD). In contrast with MERS-CoV and SARS-CoV, SARS-CoV-2 applies the S1 CTD to interact with ACE2 (Wang Q et al., 2020). It is reported that the combination of spikes and ACE2 promotes the dissociation of the S1 with ACE2, which results in the transition of S2 to mediate fusion with cell membrane (Gui et al., 2017). The role of ACE2 in mediating entry of the virus also is highlighted (Hoffmann et al., 2020; Zhou P et al., 2020). Binding of virus to ACE2 is an important initiation of viral infections, thus any drugs prevent the process can be identified as a treatment option for COVID-19. Convalescent plasma (CP) and immunoglobins (IG) collected from recovery COVID-19 patients contain neutralizing antibodies, which could bind to S1$\mathrm{RBD}$, inhibiting the binding of virus with receptor, thus limiting viral entry (Rojas et al., 2020). Umifenovir fights against SARSCoV-2 effectively by blocking or hindering trimerization of $\mathrm{S}$ protein (Vankadari, 2020). CQ/HCQ might inhibit entry process by interfering with the glycosylation of ACE2 and CQ also possesses the ability to inhibit sialic acid, which significantly affects activity of ACE2 (Kwiek et al., 2004; Hashem et al., 2020).

Entry: Coronavirus enter the host cells through two pathways: the endocytosis or membrane fusion. During the endocytosis, the viruses engulfed into a double-membrane structure firstly enter the early endosomes, and then they are mainly delivered to the late endosome, followed by fusing with lysosome. Within lysosome, the $\mathrm{S}$ protein undergoes a series of modifications and enzymatic cleavages, and then viral RNA is released into cytoplasm (Yang and Shen, 2020). Notably, the process is highly $\mathrm{pH}$-dependent and acidic environment is required. However, CQ/HCQ might neutralize their $\mathrm{pH}$ by accumulating in endosomes and lysosomes (Hashem et al., 2020; Wang M et al., 2020). Umifenovir is involved in the inhibition of membrane fusion of the viral envelope and host cell membrane (Kadam and Wilson, 2017).

RNA Replication: Coronavirus replicate the virus genomes by making use of the materials of host cells. After releasing of virus RNA into cytoplasm, the ribosomes of host cells are used to produce polyproteins, which are subsequently cleaved into smaller molecules applying for replicating new viruses by enzymes, including 3-Chymotrypsin like protease (3CLpro) and the papain-like protease (PLpro). In addition, an RNAdependent RNA polymerase (RdRp) is expressed to generate the complementary RNA strand using the virus RNA as a template (Mullard, 2018; Huang J et al., 2020; Wrapp et al., 2020). RdRp is an essential enzyme for coronavirus replication, providing a new insight for the antiviral agents for COVID-19 treatment. Remdesivir can bind with RdRp, thus RdRp is unable to incorporate RNA subunits, resulting in prevention of virus genome replication (Tchesnokov et al., 2019; Elfiky, 2020a). In addition, Ribavirin, Favipiravir and HCQ are thought to have the ability to interact with RdRp active site (Elfiky, 2020b). Zinc salts inhibits RdRp and has been shown to against coronavirus (te Velthuis et al., 2010). LPV/r have been found to tightly bind to the 
active sites of SARS-CoV-2 3CLpro, inhibiting the replication of new viruses (Nutho et al., 2020).

Transcription and release: A series of sub-genomic mRNAs are produced by discontinuous transcription and then are translated into related viral proteins. The envelope glycoproteins are newly formed and inserted into the membrane of the endoplasmic reticulum (ER) or Golgi, and the nucleocapsid consists of genomic RNA and nucleocapsid protein. Then, viral particles containing viral proteins and genome RNA can be budded into the ER-Golgi intermediate compartment. Finally, they are transported through vesicles and released out of the cell by exocytosis (Li X et al., 2020). CQ/HCQ can suppress the post-translational modification of viral proteins, which occur within the ER or trans-Golgi network (Savarino et al., 2004). The process of assembly and budding can be interfered by $\mathrm{CQ} / \mathrm{HCQ}$ with accumulation of viral vesicles in trans-Golgi network (Harley et al., 2001).

Cytokine storm: Like other viral infection, cytokines play an essential role in the progression of COVID-19. Higher levels of cytokines, including granulocyte-macrophage colony stimulating factor, monocyte-chemokine protein 1, interferon-inducible protein-10 and tumor necrosis factor- $\alpha$ (TNF- $\alpha$ ), were more commonly seen in patients with severe COVID-19 than in those with non-severe COVID-19, suggesting cytokine profiles are closely associated with COVID-19 severity (Huang C et al., 2020). The level of interleukin (IL)-2R, IL-1 and IL-6 in serum can be significantly predictors of the severity of patients with COVID-19 (Chen L et al., 2020). In addition, pathological examination of biopsy samples demonstrate that inflammatory cellular infiltration is common in multiple organs, including the lung, heart, kidney, and liver (Tian S et al., 2020; Xu Z et al., 2020). This suggests that viruses aggravate the indirect injury through proinflammatory function or cytokine storms. Therefore, monoclonal antibodies or agents targeting different cytokine also represent attractive therapeutic options for COVID-19. It is well-known that corticosteroid, CP and IG are supposed to inhibit cytokine storms and modulate dysfunctional immune system (Amoss and Chesney, 1917; McGuire and Redden, 1918; Winkler and Koepsell, 2015). By preventing or attenuating the cytokine storm by secreting powerful antiinflammatory factors, mesenchymal stem cells (MSCs) could also, theoretically, suppress overreaction of the immune system (Alhazzani et al., 2020). Various pro-inflammatory cytokines, including IL-1, IL- 6 and TNF- $\alpha$ can be reduced by the CQ/HCQ (Schrezenmeier and Dörner, 2020). Common antiTNF agents, such as infliximab, adalimumab, thalidomid and golimumab, are believed to combat cytokine release syndrome, since TNF is a vital intermediated factor in the cytokine storm (Mitoma et al., 2018). Anakinra, an IL-1 receptor antagonist that blocks cytokine release, is used to treat inflammation-related diseases and can be beneficial for treating severe COVID-19 patients (Pasi et al., 2015). Tocilizumab and eculizumab (Davies and Choy, 2014) are monoclonal antibodies against IL-6 and the complement protein C5 reverse the cytokine storm respectively and improve the condition of severely COVID-19 patients.

\section{ANTI-VIRAL AGENTS}

\section{Hydroxychloroquine and Chloroquine}

CQ/HCQ exerted inhibitory effects from recognition process to cytokine storm production (Figures 1A-F). There are many clinical trials around the world including in China (Cortegiani et al., 2020). A RCT showed that high CQ dosage should not be recommended for critically ill patients with COVID-19 because of its potential safety hazards (Borba et al., 2020). Low dose of HCQ (200 mg twice a day for 7-10 days) reduces fatality of critically ill patients with COVID-19. In France, a clinical trial showed that HCQ significantly reduced viral load in patients infected with SARS-CoV-2, especially when co-administered with azithromycin (Gautret et al., 2020a), which was supported by the conclusion of another study (Gautret et al., 2020b). Furthermore, a clinical trial showed that $\mathrm{CQ}$ may have a slight advantage over $\mathrm{LPV} / \mathrm{r}$ in combating SARS-CoV-2 (Huang M et al., 2020). However, the results of recent studies against these promising conclusions. Though, HCQ was reported to promote viral load reduction/disappearance in COVID-19 patients and the effect was reinforced by azithromycin, it is limited by the sample size (Gautret, et al., 2020a). A study showed no significantly reduced requirement for mechanical ventilation or decreased overall mortality in patients treated with HCQ (Magagnoli et al., 2020), another research didn't support its use in patients admitted to hospital with COVID-19 who require oxygen, either (Vinetz, 2020). Treatment with HCQ, azithromycin, or both, compared with neither treatment, was not significantly associated with differences in in-hospital mortality among patients with COVID-19 (Rosenberg et al., 2020). No evidence supported the beneficial effects of application of HCQ for COVID-19 patients who require oxygen (Mahévas et al., 2020). In terms of viral RNA clearance, administration of HCQ did not result in a significantly higher probability of negative conversion than standard of care alone in patients with mainly persistent mild to moderate COVID-19 (Tang W et al., 2020). Neither a multi-center RCT nor a retrospective study demonstrated HCQ shorten viral shedding in non-severe COVID-19 patients (Chen C P et al., 2020). Even in mild, early stage outpatients, HCQ did not substantially reduce symptom severity (Skipper et al., 2020). It was not associated with either a greatly lowered or an increased risk of the composite end point of intubation or death (Geleris et al., 2020). Notably, clinicians should pay more attention to the adverse effects caused by $\mathrm{CQ} / \mathrm{HCQ}$. CQ/HCQ showed retinal toxicity after long-term use for systemic lupus erythematosus and other rheumatoid diseases but some researchers believe the likelihood of retinal damage in COVID-19 patients seems to be extremely low because the dose is 3-4-fold lower than the normal dose and the duration of treatment is much shorter (Marmor, 2020). CQ/HCQ have also been associated with QT interval prolongation (Mercuro et al., 2020) and may thus lead to cardiac arrests (Lecuit, 2020), so QT interval should be followed repeatedly in patients with COVID19 who are treated with HCQ/AZ (Chorin et al., 2020). A study of case series revealed key limitations, which include a potential lack of generalizability beyond the ICU, because of cardiac 


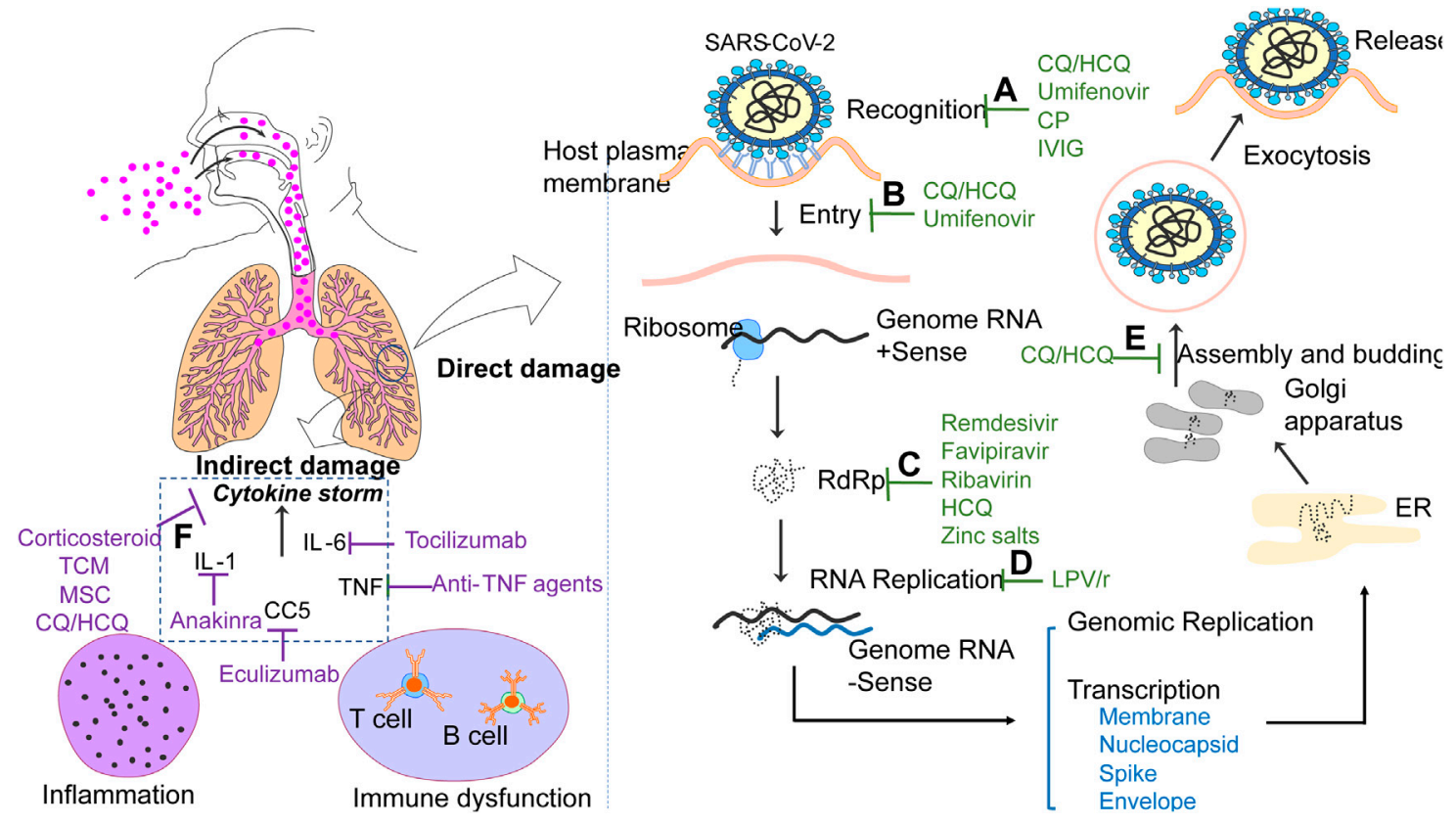

FIGURE 1 | Cellular and molecular possible sites of action of agents for COVID-19 treatment. 1. CP and IVIG inhibit the binding of virus with receptor by interacting with S1-RBD. Umifenovir interfere the recognition by blocking or hindering trimerization of S protein, while $C Q / H C Q$ interferes with the activity of $A C E 2$. 2. CQ/HCQ inhibit virus $\mathrm{pH}$-dependent endocytosis through increasing $\mathrm{pH}$. Umifenovir is also involved in the inhibition of membrane fusion. 3. Remdesivir, Ribavirin, Favipiravir, HCQ and Zinc salts can bind with RdRp, resulting in prevention of virus genome replication. 4 . LPV/r inhibit the replication of new viruses by tightly binding to the active sites of virus3CLpro 5. CQ/HCQ suppress the assembly and budding of virus. 6. Treatment strategies reduce tissues damage by targeting various cytokine storms.

complication (Bessière et al., 2020). The cardiac safety profile may, however, be ameliorated by using single enantiomers of CQ/ HCQ (Lentini et al., 2020). Serious cutaneous adverse reactions, fulminant hepatic failure and other side effects have also been reported (Ferner and Aronson, 2020). Because CQ has also been shown to reduce glucose-6-phosphate dehydrogenase (G6PD) activity, care should be taken when administering HCQ and CQ to G6PD-deficient patients, who may be more susceptible to SARS-CoV-2 (Kassi et al., 2020). The known and potential benefits of chloroquine and hydroxychloroquine no longer outweigh the known and potential risks, so that FDA revoked the emergency use. Recently, HCQ is further proposed as postexposure prophylaxis, unfortunately, two studies showed that it could not prevent SARS-CoV-2 infection (Boulware et al., 2020; Mitja et al., 2020). Basically, conflicting conclusion from current research, high possibility of adverse effects and lack of clinical trials in large population restrict CQ/HCQ use.

\section{Remdesivir}

Remdesivir fights against virus by interacting with RdRp active site to inhibit virus replication (Figure 1C). In view of it antiviral capacity, researches show significant in vitro activity of remdesivir against different viruses, including Ebola virus, Paramyxoviridae, Pneumoviridae (Lo et al., 2017) and many coronaviruses (Sheahan et al., 2017). Administration of remdesivir in both animal model and patients with Ebola showed amelioration of symptoms (Jacobs et al., 2016; Warren et al., 2016). Hence, the clinical potential of remdesivir is now being re-examined by clinicians as a result of the current SARSCoV-2 pandemic (Ko et al., 2020). In the first confirmed case of SARS-Cov-2 in the United States, the patient's oropharyngeal swab tested turned negative after administration of remdesivir for 6 days (Holshue et al., 2020). Remdesivir can also benefit patients with SARS-CoV-2 pneumonia hospitalized outside ICU where clinical outcome was better and adverse events are less frequently observed (Antinori et al., 2020). Additionally, a simulated twoarm controlled study corroborated the efficacy of remdesivir, including reducing death, increasing rate of discharge (Hsu et al., 2020). Compared to placebo group, remdesivir accelerates recovery in adult patients and decreased respiratory tract infection rate (Beigel et al., 2020). Remdesivir was related to significantly greater recovery and $62 \%$ reduced odds of death vs. standard-of-care treatment in severe patients (Olender et al., 2020). A special population, pregnant and postpartum women, with severe COVID-19 receiving compassionate use remdesivir, got high recovery rates and were at a low-risk suffering from serious adverse events (Burwick et al., 2020). However, a 5-days course and a 10-days course of remdesivir did not make any difference in patients with severe Covid-19 not requiring mechanical ventilation (Goldman et al., 2020). A RCT indicated difference of clinical status between a 5-days course of remdesivir and standard care was of uncertain clinical importance (Spinner et al., 2020). More disappointingly, accordingly to a clinical trial, compared with placebo group, remdesivir neither speeded up recovery nor reduced death in COVID-19 patients, but the true effectiveness was uncovered by 
lack of new enrolled patients in Wuhan (Grein et al., 2020). A randomized, double-blind, placebo-controlled, multicenter trial showed remdesivir was not associated with statistically significant clinical benefits among adult patients admitted to hospital for severe COVID-19. However, the numerical reduction in time to clinical improvement in those treated earlier requires confirmation in larger studies (Wang Y et al., 2020). By the way, one note of caution is that high doses of remdesivir may induce testicular toxicity and result in deterioration of sperm parameters in mice (Fan et al., 2020). Given the low certainty evidence for critical outcomes and promising faster clinical improvement for the treatment of SARS-CoV-2, use of remdesivir is weakly recommended. Ongoing trials, together with further randomized controlled trials following ethical approval, are needed to fully evaluate the efficacy and safety of remdesivir.

\section{Lopinavir and Ritonavir}

$\mathrm{LPV} / \mathrm{r}$ inhibits viral replication by binding to the active sites of SARS-CoV-2 3CLpro (Figure 1D). For SARS-CoV-2, LPV/r shows promising prospect based on clinical investigations. A report of case series showed significant signs of improvement in pneumonia-associated symptoms after antiviral treatment including LPV/r (Wang Z et al., 2020). Other reported cases described decreased viral load and clinical improvement after LPV/r administration (Han et al., 2020; Li Y et al., 2020a; Lim et al., 2020; Wang Z et al., 2020). Earlier administration of LPV/ r treatment could shorten viral shedding (Yan et al., 2020). Compared with adjuvant drugs alone, the combination of adjuvant drugs and LPV/r could lower the body temperature and restore normal physiological mechanisms with no evident toxic and side effects (Ye X T et al., 2020). Triple combination of interferon beta-1b, LPV/r and ribavirin were safe and superior to $\mathrm{LPV} / \mathrm{r}$ alone in alleviating symptoms and shortening the duration of viral shedding and hospital stay in patients with mild to moderate COVID-19 (Hung et al., 2020). However, the 28-days mortality of severe COVID-19 patients treated with $\mathrm{LPV} / \mathrm{r}$ was similar with those of patients in the standard care group (Cao B et al., 2020; Stower, 2020). A randomized trial concluded that $\mathrm{LPV} / \mathrm{r}$ was not associated with hospital stay, or risk of progressing to invasive mechanical ventilation or death, which do not support use for treatment of patients admitted to hospital with COVID-19 (RECOVERY Collaborative Group, 2020). In addition, the use of $\mathrm{LPV} / \mathrm{r}$ was even associated with delayed clearance of viral RNA (Chen X et al., 2020). In a study carried out in Singapore, however, four out of five patient $(80 \%)$ developed nausea, vomiting, and/or diarrhea, which precluded completion of the planned 14-days treatment course (Young et al., 2020). Severe jaundice was more frequently observed in patients treated with LPV/r (Levy et al., 2020). Based on pharmacokinetics, it is difficult to recommend oral $\mathrm{LPV} / \mathrm{r}$ safe dose without compromising the benefit of the antiviral strategy (Lê et al., 2020). At present, the effectiveness and safety of $\mathrm{LPV} / \mathrm{r}$ have not yet been confirmed due to controversial results, thus more clinical evidence is required for further evaluation of efficiency and safety.

\section{Favipiravir}

Favipiravir, which could interfere with the action of RdRp (Figure 1D), was reported to be effective in reducing SARSCoV-2 infection in vitro (Wang $M$ et al., 2020). A clinical study showed that treatment with FPV was safe and had no severe adverse effects. It also improved chest CT scans and viral clearance in patients with COVID-19, with a 4-days viral clearance time for FPV vs. an 11-days time for the control group (Cai et al., 2020), although the 7-days clinical recovery rate remains controversial (Chen $\mathrm{C}$ et al., 2020). It was also found that FPV significantly improved treatment effects on COVID-19 in terms of disease progression and viral clearance (Cai et al., 2020). Yet, another prospective study suggested viral clearance measured by RT-PCR by day 6 was not significantly advanced but FPV reduced time to defervescence (Doi et al., 2020). Addition of FPV into existing standard treatment was not proved to be beneficial, either (Lou et al., 2020). Oral administration of FPV even delayed viral clearance according a case series (Fu et al., 2020) and the adverse effect, fever, was firstly reported in two cases (Takoi et al., 2020). Favipiravir has been approved by the National Medical Products Administration of China as the first anti-COVID-19 drug in China, as the clinical trial had demonstrated efficacy with minimal side effects.

\section{Umifenovir}

Umifenovir was involved in the prevention of recognition and the inhibition of membrane fusion to fight against virus (Figure 1B). It is shown in vitro that umifenovir reduced replication of SARSCoV-2 compared with the control group, and the inhibition occurred efficiently at both viral entry and post-entry stages (Wang X et al., 2020). However, little benefit of umifenovir monotherapy was presented for improving the clinical outcome of mild/moderate COVID-19 patients' over supportive care. This clinical trial involving 86 patients with mild COVID-19 found that the average time for SARS-CoV-2 positive-to-negative conversion in the umifenovir group was similar to that in the control group (Li Y et al., 2020a; Li Y et al., 2020b). There were also no significant differences in symptoms, or chest CT scans between the umifenovir and favipiravir groups, suggesting that umifenovir is less suitable for first-line treatment (Chen C et al., 2020). Patients in the umifenovir group had a shorter duration of positive RNA test compared to those in the lopinavir/ritonavir group (Zhu et al., 2020). However, a recent retrospective study indicated umifenovir might not improve the prognosis or accelerate SARS-CoV-2 clearance in non-ICU patients (Lian et al., 2020). Debating of umifenovir treatment strategy needs more evidence from clinical trials.

\section{Ivermectin}

Ivermectin is a specific inhibitor of importin- $\alpha / \beta$-dependent nuclear transport and shows antiviral potential against several RNA viruses by blocking the nuclear localization of viral proteins (Lv et al., 2018). It exerts antivirus effects toward both HIV-1 and dengue virus (DENV) with respect to the HIV-1 integrase and non-structural protein 5 (NS5) polymerase proteins, respectively (Wagstaff et al., 2012). 
Ivermectin can also dissociate the preformed host importin (IMP) $\alpha / \beta 1$ heterodimer, as well as prevent its formation (Rogers T F et al., 2020). These inhibitory effects coincide with the onset of intracellular viral RNA synthesis, as expected for a molecule that specifically targets the viral helicase (Mastrangelo et al., 2012). Based on its inhibition of RNA virus, Leon et al. suggested that treatment with ivermectin reduced cell-associated SARS-CoV-2 viral RNA by $93 \%$ after $24 \mathrm{~h}$ and by $99.8 \%$ after $48 \mathrm{~h}$, with a single treatment achieving $\sim 5000$-fold reduction in viral load (Caly et al., 2020). In patients who required higher inspired oxygen or ventilatory support, ivermectin application during treatment was associated with lower mortality (Rajter et al., 2020). As an add-on therapy, ivermectin was helpful for better effectiveness, shorter hospitalstay and relatively safe (Gorial et al., 2020). However, the approved dose of ivermectin was found to exert impact in vitro, which was challenged by a new research. To achieve an efficient plasma concentration, ivermectin use would be over 10 times higher than the approved dose, possibly resulting in adverse events (Schmith et al., 2020). The optimal dose and combination strategy have not been decided so far and require more evidence from clinical studies.

\section{Galidesivir}

Galidesivir, an adenosine analogue, shows broad-spectrum antiviral activity against a wide range of RNA viruses and is under clinical development for treatment of Ebola and yellow fever virus infections. It mainly inhibits viral RdRp function, acting as a non-obligate RNA chain terminator (Warren et al., 2014). Galidesivir has been shown to treat several RNA viruses, such as Zika virus, and Rift Valley Fever virus, both in vitro and in animal model (Julander et al., 2017; Westover et al., 2018). For SARS-CoV-2, both a molecular docking study and an in silico perspective demonstrated Galidesivir can tightly bind to the RdRp of the SARS-CoV-2 strain and thus may be applied to treat the disease (Elfiky, 2020a; Elfiky, 2020b). However, ex vivo or in vivo experiment on COVID-19 is still lacking.

\section{Nelfinavir}

Nelfinavir, a well-known HIV-1 protease inhibitor, is widely prescribed as part of triple-drug combination therapy for the treatment of HIV infection. Recently, this agent also exerted inhibition on the cytopathic effect induced by SARS-CoV infection, and suppressed replication of the SARS-CoV at the post-entry step of infection (Yamamoto et al., 2004), but nelfinavir did not exhibit activity against MERS-CoV invitro (Chan et al., 2013). Several virtual screening and mocking study indicated that nelfinavir was supposed to be a potential inhibitor of COVID-19 main protease (Duan et al., 2020a; Mittal et al., 2020; Ohashi et al., 2020). In the SARS-CoV-2 research, nelfinavir mesylate might bind inside the $S$ trimer structure, which is proximal to the $S 2$ amino terminus, then directly inhibit $\mathrm{Sn}$ and So-mediated membrane fusion. This drastically inhibited $S$ proteinmediated cell fusion with complete inhibition (Musarrat et al., 2020).

\section{Other Antiviral Agents}

It seems likely that a variety of other antiviral agents will be shown to have some effects on SARS-CoV-2 replication. Baloxavir inhibits the cap-dependent endonuclease, an essential enzyme for the initiation of mRNA synthesis of influenza viruses, thus preventing transcription of mRNA (Fukao et al., 2019). Tilorone, a synthetic small-molecule compound with antiviral activity, is proposed to induce interferon against pathogenic infection (Zhang, et al., 2015), which has been confirmed in Chikungunya virus (CHIK) and MERS-CoV was described in vitro (Ekins and Madrid, 2020). Recently, the activity against SARS-CoV-2 activity was shown in a Korean study (Jeon et al., 2020). Sofobuvir, an inhibitor of RdRp, was approved for treating Zika virus and hepatitis virus $\mathrm{C}(\mathrm{HCV})$ (Sacramento et al., 2017). It was also predicted to be effective against SARS-COV-2 RdRp as well based on the molecular insight that the $\mathrm{HCV}$ and the coronavirus share a similar viral genome replication mechanism (Ju et al., 2020). Alovudine, tenofovir and alafenamide, as RdRp inhibitors, could also have same potential against COVID-19 (Chien et al., 2020). More agents together with agents referred above which are promising in COVID-19 treatment are summarized in Table 1.

\section{HOST SYSTEM MODULATORY AGENTS}

Patients infected with SARS-CoV-2 have different clinical manifestations, with a range from asymptomatic to respiratory failure, multi-organ dysfunction. Better understanding of the pathogenesis facilitates proper management of COVID-19. Patients with severe respiratory failure are more likely to present sustainable TNF- $\alpha$ and IL-6 produced by circulating monocyte, which is distinct from bacterial sepsis or influenza (Giamarellos-Bourboulis et al., 2020). COVID-19 patients are also characterized by lower platelet count and lymphocytes, increased prothrombin time, D-dimer, and fibrin degradation products with aggravating disease (Di Minno et al., 2020; Liao et al., 2020; Tang N et al., 2020b). These coagulation abnormalities are reported to cause consequences ranging from venous embolism to DIC, or even death (Connors and Levy, 2020; Piazza et al., 2020). Immune dysregulation is reported to cause hyporeactive neutrophil and neutrophil extracellular traps, which interact with platelet and fibrin, contributing to microvascular thrombi in lung, kidney, and heart (Nicolai et al., 2020). Severe COVID19 has a feature of an inflammatory signature, including high levels of inflammatory cytokines, alveolar inflammatory infiltrates, and vascular microthrombi, which leads to multiorgan failure (Chakraborty et al., 2020). Frustratingly, a WHO summary including most clinical trials and meta-analyses, concluded consistently these Remdesivir, HCQ, Lopinavir and interferon regimens mentioned above, appeared to have little or no effect on hospitalized COVID-19 (Pan et al., 2020). Due to absence of specific anti-viral agents and complicated pathogenesis of COVID-19, current treatment strategies focus on managing patients' conditions. 
Table 1 | Summary of potential agents used in the treatment of COVID-19.

\begin{tabular}{|c|c|c|c|}
\hline Agents & Property & Mechanisms & References \\
\hline NAbs & Antibody & Combine with surface epitopes of viral particles & Jeronimo et al. (2020) \\
\hline rhACE2 & Enzyme & Bind to ACE2 receptor & Zhang $\mathrm{H}$ et al. (2020) \\
\hline $\begin{array}{l}\text { Interferon } \\
\text { antagonists }\end{array}$ & Protein & Inhibit excessive interferon & Channappanavar et al. (2016) \\
\hline Baricitinib & JAK inhibitors & Restrain the JAK/STAT signaling pathway & Virtanen et al. (2019) \\
\hline Ivermectin & Anti-parasitic & Inhibit importin- $\alpha / \beta$-dependent nuclear transport & Lv et al. (2018) \\
\hline Galidesivir & Adenosine analogue & Inhibiting viral RdRp & Warren et al. (2014) \\
\hline Nelfinavir & Protease inhibitor & $\begin{array}{l}\text { Inhibit viral main protease, Inhibit S protein-mediated membrane } \\
\text { fusion }\end{array}$ & Yamamoto et al. (2004) \\
\hline Baloxavir & $\begin{array}{l}\text { Cap-dependent endonuclease } \\
\text { inhibitor }\end{array}$ & Inhibit the cap-dependent endonuclease & Fukao et al. (2019) \\
\hline Tilorone & Synthetic small-molecule compound & Induce interferon & Zhang et al. (2015) \\
\hline Sofobuvir & Adenosine analogue & Inhibit viral RdRp function & Ju et al. (2020) \\
\hline Natural killer cells & Innate immunity cell & Respond to viral infection without $\mathrm{T}$ cell help & Chen et al. (2010) \\
\hline Fingolimod & S1P modulator & Prevent egress of lymphocytes from lymph nodes & $\begin{array}{l}\text { Huwiler and Zangemeister-Wittke } \\
\text { (2018) }\end{array}$ \\
\hline Siponimod & S1P modulator & Prevent egress of lymphocytes from lymph nodes & Goodman et al. (2019) \\
\hline Metronidazole & Antibiotic and antiprotozoal & Suppress cytokines storm & Gharebaghi et al. (2020) \\
\hline Amantadine & Antiviral agent & Disrupt CTSL-mediated lysosomal pathway & Smieszek et al. (2020) \\
\hline Teicoplanin & Antibiotic & Block endocytosis of virus & Baron et al. (2020) \\
\hline Niclosamide & Anti-parasitic and anti-tumor & Block endocytosis and autophagy of virus & Pindiprolu and Pindiprolu (2020) \\
\hline Minocycline & Antibiotics & Suppress cytokines storm & Alano et al. (2006) and Ge et al. (2020) \\
\hline Triiodothyronine & Hormone & Promote the ability of natural killer cells & Pantos et al. (2020) \\
\hline Melatonin & Hormone & Suppress cytokines storm & Li Y et al. (2020) \\
\hline
\end{tabular}

ACE2: angiotensin-converting enzyme two; CTSL: Cathepsin L; JAK/STAT: Janus kinase/signal transducer and activator of transcription; NAs: Neutralizing antibodies; RdRp: RNA-dependent RNA polymerase; rhACE2: recombinant human angiotensin-converting enzyme two; S1P: sphingosine one phosphate.

\section{Corticosteroid}

Corticosteroid, which makes contributions to inhibit cytokine storm (Figure 1F), is widely used in clinical practice for years and administrated during SARS and MERS epidemic, even though there are many divergences on the treatment effect and safety issues. In terms of COVID-19, the administration of corticosteroids has again been a conundrum for clinicians. On the one hand, early, low dose and short-term application of corticosteroids was associated with a faster improvement of clinical symptoms and absorption of lung foci in patients with severe COVID-19 pneumonia (Guzik et al., 2020). Also, low dose corticosteroid therapy did not delay viral clearance in patients with COVID-19 (Cao Y et al., 2020). An early short course of methylprednisolone in patients with moderate to severe COVID-19 reduced escalation of care and improved clinical outcomes (Fadel et al., 2020). A 7-days fixed-dose course of hydrocortisone or a shock-dependent dosing of hydrocortisone, favors days reduction for organ support (Angus et al., 2020). Corticosteroid treatment was associated with a lower risk of 30days mortality, which was limited in the critically ill patients (Bartoletti et al., 2020). Despite the uncertain effect of corticosteroid therapy on overall survival, prudent dosing within effective limits may be recommended for critically ill patients under certain circumstances (Lu et al., 2020). Compared to standard use, high dose of corticosteroids (1-1.5 mg/kg/day) increased mortality exclusively in elderly patients and caused higher risk of mechanic ventilation requirement or death (Monreal et al., 2020). On the other hand, $\mathrm{Wu}$ et al. found that patients who received methylprednisolone treatment were much more likely to develop ARDS, probably because sicker patients were more likely to receive treatment, although methylprednisolone did appear to reduce the risk of death in patients with ARDS (Wu C et al., 2020). Corticosteroids impair the immune system, and current evidence does not support their use in lung injury (Russell et al., 2020). A meta-analysis showed that patients with severe conditions are more likely to require corticosteroids, but the use may lead to increased mortality and serious adverse reactions (Yang Z et al., 2020). Another study also showed no association between corticosteroid therapy and virus clearance time (Ding C et al., 2020), length of hospital stay or duration of symptoms (Jin et al., 2020). Short course use of methylprednisolone did not reduce mortality in the overall population with regard to a double-blind RCT (Jeronimo et al., 2020). Corticosteroid use showed no benefit in reducing in-hospital mortality for severe or critical cases, so the routine use of systemic corticosteroid among severe and critical COVID-19 patients was not recommended (Wu J et al., 2020). A RCT gives the conclusion that low-dose hydrocortisone didn't significantly decrease death and duration of persistent respiratory support (Dequin et al., 2020).

In view of the current evidence and clinical experience, among adults receiving mechanical ventilation who do not have ARDS, routine use of systematic corticosteroids is advised against (weak recommendation, LQE). In those with ARDS, use of corticosteroids is advised (weak recommendation, LQE) (Poston, et al., 2020). For adults with COVID-19 and refractory shock, low dose corticosteroid therapy ("shock-reversal"), is recommended over no corticosteroid treatment. A typical corticosteroid regimen in septic shock is intravenous hydrocortisone (200 $\mathrm{mg}$ per day), administered either as an infusion or as intermittent doses (Alhazzani, et al., 2020). Large, well-designed clinical trials are needed to clarify the benefits of specific administration of corticosteroids in COVID-19. 


\section{Convalescent Plasma and Immunoglobins} Neutralizing antibodies contained in CP and IVIG could bind to S1-RBD, resulting in limiting viral entry (Figure 1A). In COVID$19, \mathrm{CP}$ is an undeniable choice for administration to patients for its specificity. Observational studies of patients in Wuhan showed that CP was an effective and specific therapy for COVID-19, which decreased viral load (Ye $\mathrm{M}$ et al., 2020). 80\% recipients showed significant increase in antibody levels posttransfusion of CP in spite of variable titers from donors (Madariaga et al., 2020). When combined with systemic corticosteroids in severely ill patients, $\mathrm{CP}$ contributed to a reduction in viral load and caused no severe adverse effects (Ahn et al., 2020). As a conjunction to conventional therapy, CP speeded up being free of invasive mechanical ventilation support and elevated recovery rate (Gemici et al., 2020). Uncontrolled case series of patients, including a pregnant woman, recovered from COVID19 after transfusion with CP (Chen X et al., 2020; Shen et al., 2020). Another study including 10 patients also got good outcomes and came up that one dose of $200 \mathrm{ml}$ of CP derived from recently recovered donors with the neutralizing antibody titers above 1:640 is effective (Duan et al., 2020a). Duan et al. analyzed the feasibility of using CP in 19 patients and showed that one dose $(200 \mathrm{ml})$ was well-tolerated and improved clinical outcomes (Duan et al., 2020b). A study in Texas indicated that administration of $\mathrm{CP}$ is a safe treatment option for those with severe COVID-19 disease, although the efficacy remained unclear (Salazar et al., 2020). Analysis of case series demonstrated $\mathrm{CP}$ was safe and might be efficacious as well (Pal et al., 2020). The transfusion of $\mathrm{CP}$ is safe in 5,000 hospitalized patients with COVID-19 based on early indicators, such as transfusionassociated circulatory overload (Joyner et al., 2020). Moreover, a multicenter retrospective cohort study in China, which recruited 325 critically ill adult patients from eight treatment centers, concluded that early administration of high dose IVIG significantly reduced mortality, decreased the inflammatory response and improved the function of some organs (Shao et al., 2020). In addition, a critically ill patient was cured successfully with plasma exchange followed by IVIG (Shi et al., 2020). Nevertheless, CP did not result in a statistically significant improvement in time to clinical improvement within 28 days ( $\mathrm{Li} \mathrm{L}$ et al., 2020). There was neither difference in risk of mortality or rate of hospital discharge between CP and control group (Rogers R et al., 2020), nor could progression to severe COVID-19 or all cause morality be ameliorated by CP (Agarwal et al., 2020). Recently, CP was reported to end SARS-CoV-2 shedding but not reduce the mortality rate in critically ill patients with end-stage COVID-19, which suggested treatment should be initiated earlier (Zeng et al., 2020). The optimal dose of CP or IVIG and time of administration needs further investigation in larger well-controlled trials to fully evaluate the clinical benefits.

\section{Neutralizing Antibodies (NAbs)}

NAbs, which prevent viral attachment and accumulation, reduce infectivity by combining with surface epitopes of viral particles and blocking access of the virus to cells (Klasse, 2014). The constant region of the $\mathrm{Ab}$ can contribute to viral clearance through opsonization or complement activation, providing a highly specific immune defense (Coughlin and Prabhakar, 2012). Because SARS-CoV and SARS-CoV-2 both use ACE2 as an entry receptor (Tian $\mathrm{X}$ et al., 2020) and the receptorbinding domains (RBDs) of the two viruses are similar (Wan Y et al., 2020), NAbs against SARS may be effective in COVID-19 patients. Tian et al. (Tian X et al., 2020) recently showed that CR3022, a SARS-CoV NAb, binds to the RBD of SARS-CoV-2, although with an uncertain capability of neutralization. Some of the SARS-CoV-specific neutralizing antibodies that target the ACE2 binding site of SARS-CoV failed to bind 2019-nCoV spike protein, implying that the difference in the RBD of SARS-CoV and 2019-nCoV has a critical impact for the cross-reactivity of neutralizing antibodies. Bamlanivimab, a neutralizing IgG1 monoclonal antibody ( $\mathrm{mAb}$ ) directed against the spike protein of SARS-CoV-2, has been approved by FDA for treatment of mild-to-moderate COVID-19 in adult and pediatric patients (Coronavirus, 2020). A recent research even provided 11 potent human neutralizing antibodies for COVID-19 as therapeutic candidates (Wan J et al., 2020). Among NAbs isolated of from a convalescent patient, B38 and H4 block the binding between virus S-protein RBD and cellular receptor ACE2, displaying neutralization abilities. As for feasibility issues, NAbs is not only obtained from convalescent patients but also can be engineered in the laboratory (Zhao et al., 2015a; Zhao et al., 2015b; Li et al., 2017).

\section{Traditional Chinese Medicine}

TCM has a long history and plays an indispensable role in the treatment of diseases because of its important roles in regulating immune system and inhibiting cytokine storm (Figure 1F). During the SARS epidemic in 2003, TCM was widely used in $58.3 \%$ of confirmed cases and achieved remarkable therapeutic effects. Based on previous experience of treating SARS with TCM, clinicians, especially in China, have encouraged the integrated use of TCM and Western medicine to treat COVID-19, and TCM has been included in the guidelines for COVID-19 treatment in China. Among 701 confirmed cases treated with Qingfei Paidu decoction (QPD), 130 cases were cured and discharged, clinical symptoms disappeared in 51 cases and improved in 268 cases, and symptoms remained stable, with no deterioration, in 212 cases (Publicity Department of the People's Republic of China, 2020). Another investigation reviewed the results from four provincial hospitals in China that used QPD to treat 214 COVID-19 patients, taking three days as a course of treatment, and found that the total effective rate was $>90 \%$. The symptoms and imaging results of $60 \%$ of patients improved significantly and $30 \%$ of patients had stable symptoms without exacerbation (National Administration of Traditional Chinese Medicine, 2020). Another popular candidate, Lianhuaqingwen (LH), was shown to significantly inhibit SARS-CoV-2 replication in Vero E6 cells and markedly reduce production of pro-inflammatory cytokines (TNF- $\alpha$, IL-6, CCL-2/MCP-1 and CXCL-10/IP-10) (Runfeng et al., 2020), suggesting that it might be a potential option for COVID-19 treatment. Several observational studies suggested that $\mathrm{LH}$ accelerated the disappearance of clinical symptoms, shortened the time for conversion to virus-negative status, and accelerated 
the improvement in chest CT scans (Cheng Deizhong et al., 2020; Lyu Ruibing and Li, 2020; Yao et al., 2020; Yi, 2020). A recent multicenter, prospective, RCT indicated LH achieved a higher recovery rate and a shorter recovery without reported adverse effects. Combination use of Lianhuaqingwen and umifenovir may accelerate recovery and improve the prognosis of patients with moderate COVID-19 (Fang et al., 2020). Another Chinese herbal extract, Xuebijing, also reduced the time for conversion to virusnegative status (Zhang C et al., 2020). Three cases from the same family, who received Western medicine combined with the Chinese traditional patent medicine Shuanghuanglian oral liquid, were reported to make a rapid recovery ( $\mathrm{Ni}$ et al., 2020). Tanreqing capsule, significantly reduced the negative conversion time of fecal nucleic acid and the duration of negative conversion of pharyngeal-fecal nucleic acid (Zhang $\mathrm{X}$ et al., 2020). A retrospective study of four cases indicated that combination of Chinese and Western medicine improved the pneumonia-associated symptoms of COVID-19 (Wang Z et al., 2020). Both data mining of on-line databases and a core outcome set also concluded that TCM is effective for management of COVID-19 (Qiu et al., 2020; Zhou Z et al., 2020). Although highquality evidence for the safety of some Chinese herbs is lacking (Luo et al., 2012), when used correctly based on patients' situation, it is generally believed that there are no serious adverse reactions.

\section{Mesenchymal Stem Cells}

Attention has been paid to the role of MSCs in attenuating the cytokine storm and suppressing overreaction of the immune system (Figure 1F). Clinical trials of different types of MSCs in COVID-19 patients are ongoing. Seven patients with SARSCoV-2 pneumonia showed improved clinical outcomes without observed adverse effects after intravenous injection with bone marrow-derived MSCs for 14 days (Leng et al., 2020). MSC transplantation improved oxygen saturation for ARDS and increased the immune indicators, including CD4 and lymphocytes (Tang L et al., 2020). Treatment with adiposederived stromal stem cells (ASCs) also shows promise in combating SARS-CoV-2 (Gentile and Sterodimas, 2020). 13 severe COVID-19 patients who were intravenously injected with ASC, mostly were extubated and discharged from ICU, with no significant adverse events (Sanchez-Guijo et al., 2020). Among stem cells, umbilical cord stem cells seem to be most desirable for treating SARS-CoV-2, because of noninvasive extraction procedures, fast doubling times and greater plasticity (Misra et al., 2020). Adoptive transfer therapy using human umbilical cord mesenchymal stem cells in a critically ill, 65-year-old patient with COVID-19, was well tolerated and led to a significant clinical improvement (Bing Liang et al., 2020). A phase one clinical trial revealed human umbilical cord mesenchymal stem cells was safe and well-tolerated by intravenous injection (Meng et al., 2020). Incidence of disease deterioration or severe complication of MSC treatment was rarely seen (Atluri et al., 2020). A novel technology for capturing the therapeutic properties of stem cells using nanotechnology has provided a new sight into MSC therapy (Metcalfe, 2020). Because of the complexities and ethical issues surrounding the use of MSCs, further clinical trials, with the highest standards of rational and appropriate design are needed (Khoury et al., 2020).

\section{Tocilizumab}

It is well known that tocilizumab as a monoclonal antibody improving inflammatory condition by fighting against IL-6 (Figure 1F). A study in COVID-19 patients showed that intravenous administration of tocilizumab $(8 \mathrm{mg} / \mathrm{kg}$ every $8 \mathrm{~h}$ ) was highly beneficial (Michot et al., 2020). An Italian study also found that a patient who received tocilizumab $(8 \mathrm{mg} / \mathrm{kg}$ every $12 \mathrm{~h})$ for 2 days showed progressive improvements in both clinical condition and chest CT scans (Cellina et al., 2020). A single-dose use of tocilizumab, improved survival (Rossi B et al., 2020) and reduced lethality rate at 30 days with no significant toxicity in severe COVID-19 patients, who were without mechanical ventilation (Perrone et al., 2020). Response of COVID-19 pneumonia with ARDS to tocilizumab was rapid, sustained, and associated with significant clinical improvement, reduced mortality, and no obvious adverse reactions (Sciascia et al., 2020; Toniati et al., 2020; Xu X et al., 2020). It also shows short-term survival benefit in patients with severe COVID-19 illness (Ramaswamy et al., 2020). Treatment of a sickle cell patient infected with SARS-CoV-2 with tocilizumab and hydroxychloroquine led to a significant improvement in clinical condition (De Luna et al., 2020). In a preprint study, 30 selected patients showed that tocilizumab significantly reversed the cytokine storm and improved the condition of severely ill patients. The dosage of tocilizumab for COVID-19 patients can be determined based on those used to treat rheumatoid arthritis (Instruction of Tocilizumab, 2020). Time from lung injury onset to tocilizumab administration may be critical to patient recovery (Sanchez-Montalva et al., 2020). Early use lead to a positive impact during Covid-19 pneumonia with severe respiratory syndrome in terms of increased survival and favorable clinical course (Capra et al., 2020). Early stage administration of tocilizumab subcutaneously reduced the risk of death and improves clinical parameters, for example, CRP and lymphocyte counts (Malekzadeh et al., 2020). In addition to relieve hyper-inflammatory reaction, it is also beneficial for patients with liver dysfunction (Serviddio et al., 2020). Although tocilizumab group seemed to have improved survival outcome, these positive results need to be interpreted with caution since different research types and confounding factors (Wadud et al., 2020). Transient transaminitis was found to be the most common adverse reaction in patients 21 days post tocilizumab (Sirimaturos et al., 2020). However, no significant clinical improvement in temperature or oxygen requirements in most patients were observed in a US study (Rimland et al., 2020). A recent RCT concluded tocilizumab failed to prevent intubation or death in moderately ill hospitalized patients (Stone et al., 2020). Despite IL-6 receptor inhibitors might cause hypertriglyceridemia and acute pancreatitis (Morrison et al., 2020), tocilizumab is among the candidates for antiinflammatory treatment in COVID-19. 


\section{Other Anti-cytokines Therapeutics}

Common anti-TNF agents, such as infliximab, adalimumab, thalidomid and golimumab (Mitoma et al., 2018), could be functional in inflammatory diseases. Common anti-TNF agents, such as infliximab, adalimumab, thalidomid and golimumab (Mitoma et al., 2018), could be functional in inflammatory diseases. A patient with IBD and COVID-19, was given adalimumab therapy, generated a quicker hospital discharge (Tursi et al., 2020). A patient with COVID-19 treated by thalidomide (Wang, 2020), got clinical improvements. Certainly, safety and efficiency need more support from clinical trials. Another anti-inflammation candidate, anakinra may be beneficial for treating severe COVID-19 patients with secondary HLH (Dimopoulos et al., 2020). Anakinra was used on nine consecutive severe COVID-19 pneumonia patients, and early chest CT scan showed the stopped extension of lesions. In this small open-label study, anakinra use was safe (Aouba et al., 2020). Although there is a shortage of relevant research about IL-1 receptor antagonists in COVID-19 patients, anakinra could potentially be beneficial in these patients. Additionally, Eculizumab, an agent that blocks the C5a pathway, should mitigate damage in COVID-19 patients and a 4-weeks study treatment with eculizumab did indeed remarkably improve the conditions of severe pneumonia or ARDS in COVID-19 patients, a finding that was supported by subsequent CT scans (Diurno et al., 2020). This discovery highlights a novel effective anti-inflammatory treatment, focusing on the complement system, which is worthy of further exploration as a treatment for COVID-19.

\section{Interferon Antagonists}

Interferon, a glycoprotein with broad spectrum antiviral activity produced by innate immune cells, plays an important role in coronavirus infection (Hadjadj et al., 2020; Huang L et al., 2020; Volk et al., 2020). Interferon is a double-edged sword in viral diseases. On one hand, SARS$\mathrm{CoV}$ encodes several proteins, including nsp13, nsp14, nsp15 and ORF6 (Yuen et al., 2020), that modulate innate immune signaling through the potential antagonism of the induction of interferon and by avoidance of interferon stimulated gene (ISG) effector functions (Totura and Baric, 2012). Downregulation of interferon expression assists SARS-CoV2 infection because interferon is essential to prevent entry of coronaviruses into host cells (Volk et al., 2020). In addition, Interferon alfa-2a combined with ribavirin therapy is associated with significantly improved survival in MERS (Omrani et al., 2014). On the other hand, delayed IFN-I signaling promotes the accumulation of pathogenic inflammatory monocyte-macrophages (IMMs), resulting in elevated lung cytokine/chemokine levels, vascular leakage, and impaired virus-specific $\mathrm{T}$ cell responses in SARS-CoVinfected mice (Channappanavar et al., 2016). Early short-term blocking IFN-I after coronavirus infection evoked a longlasting enhancement of immunological memory, which conferred improved protection upon subsequent reinfections (Palacio et al., 2020). Because excessive interferon responses during SARS-CoV-2 infection may lead to tissue damage (Zhou F et al., 2020), late phase interferon antagonist treatment should be considered.

\section{JAK Inhibitors}

The JAK/STAT signaling pathway has been widely validated as a target for inflammation-related diseases (Virtanen et al., 2019). Moreover, Hadjadj et al. found an increase in peripheral blood of IL- 6 and IL-6-induced genes, TNF- $\alpha$ and TNF- $\alpha$ pathway-related genes, as well as IL-10 (Hadjadj et al., 2020). JAK-STAT activation is also known to suppress the functions of granulocyte-macrophage colony-stimulating factor (McInnes et al., 2019). All of these indicated that JAK inhibitors could potentially be used to reduce inflammation in COVID-19 patients. JAK inhibitor curded activation of ACE2 and interferon-stimulated transcriptomes in human airway epithelium (Lee et al., 2020). Because JAK2 inhibition is reversible, transient treatment would not affect $\mathrm{TH} 17$ responses that are essential for innate immune responses and immunity against extracellular pathogens (Praveen et al., 2020). Baricitinib, Ruxolitinib and upadacitinib, JAK1/JAK2/JAK3 inhibitors, emerges as a potential agent (Richardson et al., 2020). Baricitinib stopped progression toward a severe/extreme form of the viral disease by restraining immune dysregulation in COVID-19 (Bronte et al., 2020). Ruxolitinib attenuated SARSCoV-2 infection (Foss et al., 2020) and it rescued a patient who are refractory to anti-IL-6 therapy. Now, results of ongoing clinical trials will give a direction of JAK inhibitors administration.

\section{Combination of Agents}

Some research indicated good outcome when oseltamivir used with other antiviral agents, like abidol, but the effect of oseltamivir alone remains unclear (Costanzo et al., 2020; Ding Q et al., 2020; Wang D et al., 2020). Moreover, oseltamivir has not been shown to have efficacy based on all investigation summary (Sanders et al., 2020). Furthermore, a retrospective study provided the first in vivo evidence that zinc sulfate in combination with hydroxychloroquine may play a role in therapeutic management for COVID-19 (Carlucci et al., 2020). This combination will be tested as a prophylactic regimen in a randomized clinical trial.

Treatment with IFN- $\alpha 2 b$ with or without umifenovir significantly reduced the duration of detectable virus in the upper respiratory tract and in parallel reduced duration of elevated blood levels for the inflammatory markers IL-6 and CRP (Liu et al., 2020). In COVID-19, triple combination of interferon beta- $1 \mathrm{~b}$, lopinavir-ritonavir and ribavirin alleviated symptoms and shortened the duration of viral shedding and hospital stay in patients with mild to moderate COVID-19 (Hung et al., 2020). Besides, type III IFNs (IFN- $\lambda$ ) was believed to play an important role in SARS-CoV-2 and other viral infections (Prokunina-Olsson et al., 2020). Further application of interferon and combination regimen are undergoing more clinical trials.

\section{Anti-thrombotic Therapy}

Rebalancing coagulation system, especially anti-platelet and anticoagulant is crucial for COVID-19 coagulopathy administration. 
Antiplatelet therapy might be effective in improving the ventilation/perfusion ratio in COVID-19 patients with severe respiratory failure (Viecca et al., 2020). Aspirin, a classical anti-platelet agent, is possible to decrease mechanical ventilation rate, ICU admission and in-hospital mortality, without more bleeding events compared to non-aspirin use, based on evidence from a retrospective study (Chow et al., 2020). It is recommended that person suffering from SARSCoV-2 infection should be administered with aspirin at the earliest (Haque et al., 2020). For the severe COVID-19 patients meeting SIC criteria or with markedly elevated D-dimer, using low molecular weight heparin seems to be associated with better prognosis (Tang $\mathrm{N}$ et al., 2020a). Dipyridamole, prohibiting platelet from aggregating, was shown to reduce viral replication, suppress hypercoagulability and enhance immune recovery, when taken as an adjunctive therapy in COVID-19 (Liu et al., 2020). Furthermore, longer duration of anti-coagulation was associated with reduced mortality risk (Paranjpe et al., 2020). Argatroban, a direct thrombin inhibitor, decreased further thrombosis complications (Arachchillage et al., 2020). Moreover, therapeutic-strength anticoagulation performed better than prophylactic anticoagulation without contributing to bleeding events (Boonyasai et al., 2020; Ferguson et al., 2020). Therapeutic anticoagulation is associated with a survival advantage among patients with COVID-19 who require mechanical ventilation in the ICU, as well (Trinh et al., 2020). Pre-admission applying antithrombotic, however, showed little protective effect in severe patients (Russo et al., 2020). COVID-19 patients receiving anticoagulation medicine chronically, were prone to a higher mortality, resulting from cardiovascular events (Rossi $\mathrm{R}$ et al., 2020). A high incidence of venous thrombosis and worse outcome is observed, despite the use of heparin at the therapeutic dose (Pavoni et al., 2020). Routine chemical prophylaxis is believed to be inadequate in preventing venous thromboembolism in severe COVID-19, and different pharmacologic prophylaxis regimens are not helpful for lowering incidence of deep venous thrombosis (Maatman et al., 2020). High regimen thromboprophylaxis, like subcutaneous therapeutic unfractioned heparin, decreased the occurrence of pulmonary embolism (Taccone et al., 2020). Whether therapeutic or prophylaxis anti-thrombotic to be used, monitoring D-dimer is helpful for measuring efficiency and preventing adverse events (Song et al., 2020). Specific anticoagulation regimens may vary in different disease severity and need further determination based on clinical trials.

\section{Micronutrients Supplementation}

Providing patients with sufficient nutrients through all stages of COVID-19 is also vital. Micronutrients, such as vitamin D, which is a modulator of adaptive immunity, may also be important. Serum concentrations of 25-hydroxy vitamin D tend to decrease with age (Vásárhelyi et al., 2011), and this may be associated with the severity of COVID-19 in the elderly (Novel, 2020). Moreover, vitamin D deficiency served as a predictor of high severity/mortality and poor prognosis in patients with acute respiratory failure due to COVID-19
(Carpagnano et al., 2020; Radujkovic et al., 2020), and as an indicator of high infection risk for the healthy (Merzon et al., 2020). Vitamin D is supposed to lower viral replication rates and reduce concentrations of pro-inflammatory cytokines via cathelicidins and defensins (Grant et al., 2020). Due to the underlying benefits, safety and low cost, it is rational to use it as a supplementary therapeutic in COVID-19. Vitamin C is also believed to significantly lower incidence of pneumonia based on three controlled trials with human subjects (Hemilä, 1997), which suggests it may affect susceptibility to lower respiratory tract infections under certain conditions (Hemilä, 2003). A clinical trial is undergoing to access the impact of high dose of vitamin C in patients with COVID-19 (Carr and Rowe, 2020), which is closed because of rare severe cases in Wuhan. Another micronutrient, vitamin $\mathrm{K}$, its reduced level emerges as a potential risk factor of severe COVID-19 (Dofferhoff et al., 2020), suggesting supplement of vitamin K might be a necessary therapy.

\section{CONCLUSION}

The ongoing public health crisis caused by SARS-CoV-2 is receiving massive global attention. Although several vaccines are being developed to protect against SARS-CoV-2, major efforts are underway to repurpose existing drugs to treat COVID-19. Herein, we have summarized current data, from both in vitro experiments and clinical research to address the effectiveness and safety of all candidates, applied to COVID-19 administration. CQ/HCQ inhibits virus infection via different stages, yet more risk instead of benefit is shown based on clinical studies. Remdesivir, due to the promising efficiency and more supportive evidence, is acknowledged as one of the therapeutic of COVID-19. In general, highly efficient anti-viral agents are absent in current treatment strategy. As for host system modulatory agents, use of corticosteroid and TCM need to be measured according to patients' conditions, and the optimal dosage is uncertain. CP and MSC would theoretically provide passive immunity for patients and are relatively safe, however, they failed to achieve consistent results and are limited by the resources as well. Since it is well known that the incidence of thrombotic events is high, the strategy of therapeutic and prophylactic anti-thrombotic agents remains uncertain and needs to be taken into consideration. Lack of specific treatment for COVID-19 brings more attention to vaccine development to keep the pandemic in control and reduce severe condition. In summary, more large-scale randomized clinical trials are urgently required to provide high quality data and guide clinician to make better decision on treatment.

\section{AUTHOR CONTRIBUTIONS}

ZZ, TW, LP, CZ, YH, LJ, XL, ZX, XX, JL, MY and MD contribute to the material collection and manuscript writing. All authors read and approved the final manuscript. 


\section{FUNDING}

This work was supported by the National Natural Science Foundation of China under contract (Nos. 31672290, 31100764, 30901874), the National Key Research and Development Program of China (2016YFD0500300), Zhejiang University Special Scientific Research Fund for COVID-19 Prevention and Control (2020XGZX033), Science and Technology Plan Project of Changsha (Nos. kq2001033, kq2001012), the Natural Science

\section{REFERENCES}

Agarwal, A., Mukherjee, A., Kumar, G., Chatterjee, P., Bhatnagar, T., and Malhotra, P. (2020). Convalescent plasma in the management of moderate covid-19 in adults in India: open label phase II multicentre randomised controlled trial (PLACID Trial). Br. Med. J. 371, m3939. doi:10.1136/bmj.m3939

Ahn, J. Y., Sohn, Y., Lee, S. H., Cho, Y., Hyun, J. H., Baek, Y. J., et al. (2020). Use of convalescent plasma therapy in two COVID-19 patients with acute respiratory distress syndrome in Korea. J. Kor. Med. Sci. 35 (14), e149. doi:10.3346/jkms. 2020.35.e149

Alano, C. C., Kauppinen, T. M., Valls, A. V., and Swanson, R. A. (2006). Minocycline inhibits poly(ADP-ribose) polymerase-1 at nanomolar concentrations. Proc. Natl. Acad. Sci. U. S. A. 103 (25), 9685-9690. doi:10. 1073/pnas.0600554103

Alhazzani, W., Moller, M. H., Arabi, Y. M., Loeb, M., Gong, M. N., Fan, E., et al. (2020). Surviving Sepsis Campaign: guidelines on the management of critically ill adults with Coronavirus Disease 2019 (COVID-19). Intensive Care Med. 46 (5), 854-887. doi:10.1007/s00134-020-06022-5

Amoss, H. L., and Chesney, A. M. (1917). A report on the serum treatment of twenty-six cases of epidemic poliomyelitis. J. Exp. Med. 25 (4), 581-608. doi:10. 1084/jem.25.4.581

Angus, D. C., Derde, L., Al-Beidh, F., Annane, D., Arabi, Y., Beane, A., et al. (2020). Effect of hydrocortisone on mortality and organ support in patients with severe COVID-19: the REMAP-CAP COVID-19 corticosteroid domain randomized clinical trial. Jama 324 (13), 1317-1329. doi:10.1001/jama.2020.17022

Antinori, S., Cossu, M. V., Ridolfo, A. L., Rech, R., Bonazzetti, C., Pagani, G., et al. (2020). Compassionate remdesivir treatment of severe Covid-19 pneumonia in intensive care unit (ICU) and Non-ICU patients: clinical outcome and differences in post_treatment hospitalisation status. Pharmacol. Res. 158, 104899. doi:10.1016/j.phrs.2020.104899

Aouba, A., Baldolli, A., Geffray, L., Verdon, R., Bergot, E., Martin-Silva, N., et al. (2020). Targeting the inflammatory cascade with anakinra in moderate to severe COVID-19 pneumonia: case series. Ann. Rheum. Dis. 79, 1381. doi:10. 1136/annrheumdis-2020-217706

Arachchillage, D. J., Remmington, C., Rosenberg, A., Xu, T., Passariello, M., Hall, D., et al. (2020). Anticoagulation with argatroban in patients with acute antithrombin deficiency in severe COVID-19. Br. J. Haematol. 190 (5), e286-e288. doi:10.1111/bjh.16927

Atluri, S., Manocha, V., Boddu, N., Bhati, S., Syed, Z., Diwan, S., et al. (2020). Safety and effectiveness of intravascular mesenchymal stem cells to treat organ failure and possible application in COVID-19 complications. Pain Physician 23 (4S), S391-S420.

Baron, S. A., Devaux, C., Colson, P., Raoult, D., and Rolain, J. M. (2020). Teicoplanin: an alternative drug for the treatment of COVID-19? Int. J. Antimicrob. Agents 55 (4), 105944. doi:10.1016/j.ijantimicag.2020.105944

Bartoletti, M., Marconi, L., Scudeller, L., Pancaldi, L., Tedeschi, S., Giannella, M., et al. (2020). Efficacy of corticosteroid treatment for hospitalized patients with severe COVID-19: a multicentre study. Clin. Microbiol. Infect. 25 (1), 105-111. doi:10.1016/j.cmi.2020.09.014

Beigel, J. H., Tomashek, K. M., Dodd, L. E., Mehta, A. K., Zingman, B. S., Kalil, A. C., et al. (2020). Remdesivir for the treatment of covid-19 - final report. N. Engl. J. Med. 383, 1813-1826. doi:10.1056/NEJMoa2007764

Bessière, F., Roccia, H., Delinière, A., Charrière, R., Chevalier, P., Argaud, L., et al. (2020). Assessment of QT intervals in a case series of patients with coronavirus
Foundation of Hunan Province, China (No. 2016JJ3180), Open Sharing Fund for the Large-scale Instruments and Equipments of Central South University (Nos. CSUZC2020043).

\section{ACKNOWLEDGMENTS}

We thank International Science Editing (http://www. internationalscienceediting.com) for editing this manuscript.

disease 2019 (COVID-19) infection treated with hydroxychloroquine alone or in combination with azithromycin in an intensive care unit. JAMA Cardiol. 5 (9), 1067-1069. doi:10.1001/jamacardio.2020.1787

Bing Liang, J. C., Li, T., Wu, H., Yang, W., Li, Y., Li, J., et al. (2020). Clinical remission of a critically ill COVID-19 patient treated by human umbilical cord mesenchymal stem cells. Medicine 99, e21429. doi:10.1097/MD. 0000000000021429

Boonyasai, R. T., Murthy, V. K., Yuen-Gee Liu, G., Garibaldi, B. T., Brotman, D. J., Streiff, M. B., et al. (2020). Venous thromboembolism in hospitalized patients with COVID-19 receiving prophylactic anticoagulation. Mayo Clin. Proc. 95 (10), 2291-2293. doi:10.1016/j.mayocp.2020.08.014

Booth, C. M., Matukas, L. M., Tomlinson, G. A., Rachlis, A. R., Rose, D. B., Dwosh, H. A., et al. (2003). Clinical features and short-term outcomes of 144 patients with SARS in the greater Toronto area. Jama 289 (21), 2801-2809. doi:10.1001/ jama.289.21.JOC30885

Borba, M. G. S., Val, F. F. A., Sampaio, V. S., Alexandre, M. A. A., Melo, G. C., Brito, M., et al. (2020). Effect of high vs low doses of chloroquine diphosphate as adjunctive therapy for patients hospitalized with severe acute respiratory syndrome coronavirus 2 (SARS-CoV-2) infection: a randomized clinical trial. JAMA Netw. Open 3 (4), e208857. doi:10.1001/jamanetworkopen.2020. 8857

Boulware, D. R., Pullen, M. F., Bangdiwala, A. S., Pastick, K. A., Lofgren, S. M., Okafor, E. C., et al. (2020). A randomized trial of hydroxychloroquine as postexposure prophylaxis for covid-19. N. Engl. J. Med. 383 (6), 517-525. doi:10.1056/NEJMoa2016638

Bronte, V., Ugel, S., Tinazzi, E., Vella, A., De Sanctis, F., Canè, S., et al. (2020). Baricitinib restrains the immune dysregulation in severe COVID-19 patients. J. Clin. Invest. 130, 6409-6416. doi:10.1172/jci141772

Burwick, R. M., Yawetz, S., Stephenson, K. E., Collier, A. Y., Sen, P., Blackburn, B. G., et al. (2020). Compassionate use of remdesivir in pregnant women with severe covid-19. Clin. Infect. Dis. 8, 1466. doi:10.1093/cid/ciaal466

Cai, Q., Yang, M., Liu, D., Chen, J., Shu, D., Xia, J., et al. (2020). Experimental treatment with favipiravir for COVID-19: an open-label control study. Engineering 6, 7. doi:10.1016/j.eng.2020.03.007

Caly, L., Druce, J. D., Catton, M. G., Jans, D. A., and Wagstaff, K. M. (2020). The FDA-approved drug ivermectin inhibits the replication of SARS-CoV2 in vitro. Antivir. Res. 178, 104787. doi:10.1016/j.antiviral.2020.104787

Cao, B., Wang, Y., Wen, D., Liu, W., Wang, J., Fan, G., et al. (2020). A trial of lopinavir-ritonavir in adults hospitalized with severe covid-19. N. Engl. J. Med. 382, 1787-1799. doi:10.1056/NEJMoa2001282

Cao, Y., Su, B., Guo, X., Sun, W., Deng, Y., Bao, L., et al. (2020). Potent neutralizing antibodies against SARS-CoV-2 identified by high-throughput single-cell sequencing of convalescent patients' B cells. Cell 182 (1), 73-84. doi:10. 1016/j.cell.2020.05.025

Capra, R., De Rossi, N., Mattioli, F., Romanelli, G., Scarpazza, C., Sormani, M. P., et al. (2020). Impact of low dose tocilizumab on mortality rate in patients with COVID-19 related pneumonia. Eur. J. Intern. Med. 76, 31-35. doi:10.1016/j. ejim.2020.05.009

Carlucci, P., Ahuja, T., Petrilli, C. M., Rajagopalan, H., Jones, S., and Rahimian, J. (2020). Hydroxychloroquine and azithromycin plus zinc vs hydroxychloroquine and azithromycin alone: outcomes in hospitalized COVID-19 patients. Available at: https://www.medrxiv.org/content/10.1101/ 2020.05.02.20080036v1.

Carpagnano, G. E., Di Lecce, V., Quaranta, V. N., Zito, A., Buonamico, E., Capozza, E., et al. (2020). Vitamin D deficiency as a predictor of poor prognosis in 
patients with acute respiratory failure due to COVID-19. J. Endocrinol. Invest. 2020, 1-7. doi:10.1007/s40618-020-01370-x

Carr, A. C., and Rowe, S. (2020). The emerging role of vitamin C in the prevention and treatment of COVID-19. Nutrients 12 (11), 3286. doi:10. 3390/nu12113286

Cellina, M., Orsi, M., Bombaci, F., Sala, M., Marino, P., and Oliva, G. (2020). Favorable changes of CT findings in a patient with COVID-19 pneumonia after treatment with tocilizumab. Diagn. Interv. Imaging 101, 323-324. doi:10.1016/j. diii.2020.03.010

Chakraborty, S., Gonzalez, J., Edwards, K., Mallajosyula, V., Buzzanco, A. S., Sherwood, R., et al. (2020). Proinflammatory IgG Fc structures in patients with severe COVID-19. Nat. Immunol. 22, 67-73. doi:10.1038/s41590-020-00828-7

Chan, J. F., Chan, K. H., Kao, R. Y., To, K. K., Zheng, B. J., Li, C. P., et al. (2013). Broad-spectrum antivirals for the emerging Middle East respiratory syndrome coronavirus. J. Infect. 67 (6), 606-616. doi:10.1016/j.jinf.2013.09.029

Chan, K. S., Zheng, J. P., Mok, Y. W., Li, Y. M., Liu, Y. N., Chu, C. M., et al. (2003). SARS: prognosis, outcome and sequelae. Respirology 8 (Suppl. 1), S36-S40. doi:10.1046/j.1440-1843.2003.00522.x

Channappanavar, R., Fehr, A. R., Vijay, R., Mack, M., Zhao, J., Meyerholz, D. K., et al. (2016). Dysregulated type I interferon and inflammatory monocytemacrophage responses cause lethal pneumonia in SARS-CoV-infected mice. Cell Host Microbe 19 (2), 181-193. doi:10.1016/j.chom.2016.01.007

Chen, C., Zhang, Y., Huang, J., Yin, P., Cheng, Z., Wu, J., et al. (2020). Favipiravir versus arbidol for COVID-19: a randomized clinical trial. medRxiv 2003, 20037432. doi:10.1101/2020.03.17.20037432

Chen, C.-P., Lin, Y.-C., Chen, T.-C., Tseng, T.-Y., Wong, H.-L., Kuo, C.-Y., et al. (2020). A Multicenter, randomized, open-label, controlled trial to evaluate the efficacy and tolerability of hydroxychloroquine and a retrospective study in adult patients with mild to moderate Coronavirus disease 2019 (COVID-19). PLoS One 15, e0242763. doi:10.1371/journal.pone.0242763

Chen, J., Lau, Y. F., Lamirande, E. W., Paddock, C. D., Bartlett, J. H., Zaki, S. R., et al. (2010). Cellular immune responses to severe acute respiratory syndrome coronavirus (SARS-CoV) infection in senescent $\mathrm{BALB} / \mathrm{c}$ mice: $\mathrm{CD} 4+\mathrm{T}$ cells are important in control of SARS-CoV infection. J. Virol. 84 (3), 1289-1301. doi:10. 1128/jvi.01281-09

Chen, L., Liu, H. G., Liu, W., Liu, J., Liu, K., Shang, J., et al. (2020). [Analysis of clinical features of 29 patients with 2019 novel coronavirus pneumonia]. Zhonghua Jiehe He Huxi Zazhi 43, E005. doi:10.3760/cma.j.issn.1001-0939. 2020.0005

Chen, X., Zhang, Y., Zhu, B., Zeng, J., Hong, W., He, X., et al. (2020). Associations of clinical characteristics and antiviral drugs with viral RNA clearance in patients with COVID-19 in Guangzhou, China: a retrospective cohort study. Available at: https://www.medrxiv.org/content/10.1101/2020.04.09.20058941v1.

Chen, Y., Liu, Q., and Guo, D. (2020). Emerging coronaviruses: genome structure, replication, and pathogenesis. J. Med. Virol. 92 (4), 418-423. doi:10.1002/jmv. 25681

Cheng Deizhong, W. W., Yi, Li., Wu, X., Zhou, B., and Song, Q. (2020). 51 cases of new coronavirus pneumonia patients treated with Chinese medicine Analysis of the efficacy of Lianhua Qingwen: a multi-center retrospective study. Available at: http://kns.cnki.net/kcms/detail/12.1349.R.20200310.1024.004.html.

Chien, M., Anderson, T. K., Jockusch, S., Tao, C., Kumar, S., Li, X., et al. (2020). Nucleotide analogues as inhibitors of SARS-CoV-2 polymerase. Available at: https://www.biorxiv.org/content/10.1101/2020.03.18.997585v1.

Chorin, E., Dai, M., Shulman, E., Wadhwani, L., Bar-Cohen, R., Barbhaiya, C., et al. (2020). The QT interval in patients with COVID-19 treated with hydroxychloroquine and azithromycin. Nat. Med. 26 (6), 808-809. doi:10. 1038/s41591-020-0888-2

Chow, J. H., Khanna, A. K., Kethireddy, S., Yamane, D., Levine, A., Jackson, A. M., et al. (2020). Aspirin use is associated with decreased mechanical ventilation, ICU admission, and in-hospital mortality in hospitalized patients with COVID19. Anesth. Analg. doi:10.1213/ane.0000000000005292

Connors, J. M., and Levy, J. H. (2020). COVID-19 and its implications for thrombosis and anticoagulation. Blood 135 (23), 2033-2040. doi:10.1182/ blood.2020006000

Coronavirus (2020). Coronavirus (COVID-19) update: FDA authorizes monoclonal antibody for treatment of COVID-19. Available at: https://www. fda.gov/news-events/press-announcements/coronavirus-covid-19-update-fdaauthorizes-monoclonal-antibodies-treatment-covid-19.
Cortegiani, A., Ingoglia, G., Ippolito, M., Giarratano, A., and Einav, S. (2020). A systematic review on the efficacy and safety of chloroquine for the treatment of COVID-19. J. Crit. Care 57, 279-283. doi:10.1016/j.jcrc.2020.03.005

Costanzo, M., De Giglio, M. A. R., and Roviello, G. N. (2020). SARS-CoV-2: recent reports on antiviral therapies based on lopinavir/ritonavir, darunavir/ umifenovir, hydroxychloroquine, remdesivir, favipiravir and other drugs for the treatment of the new coronavirus. Curr. Med. Chem. 27, 4536-4541. doi:10. 2174/0929867327666200416131117

Coughlin, M. M., and Prabhakar, B. S. (2012). Neutralizing human monoclonal antibodies to severe acute respiratory syndrome coronavirus: target, mechanism of action, and therapeutic potential. Rev. Med. Virol. 22 (1), 2-17. doi:10.1002/rmv.706

Davies, R., and Choy, E. (2014). Clinical experience of IL-6 blockade in rheumatic diseases - implications on IL-6 biology and disease pathogenesis. Semin. Immunol. 26 (1), 97-104. doi:10.1016/j.smim.2013.12.002

De Luna, G., Habibi, A., Deux, J. F., Colard, M., d'Alexandry d'Orengiani, A., Schlemmer, F., et al. (2020). Rapid and severe covid-19 pneumonia with severe acute chest syndrome in a sickle cell patient successfully treated with tocilizumab. Am. J. Hematol. 95, 876-878. doi:10.1002/ajh.25833

Dequin, P. F., Heming, N., Meziani, F., Plantefève, G., Voiriot, G., Badié, J., et al. (2020). Effect of hydrocortisone on 21-day mortality or respiratory support among critically ill patients with COVID-19: a randomized clinical trial. Jama 324 (13), 1298-1306. doi:10.1001/jama.2020.16761

Di Minno, M. N. D., Calcaterra, I., Lupoli, R., Storino, A., Spedicato, G. A., Maniscalco, M., et al. (2020). Hemostatic changes in patients with COVID-19: a meta-analysis with meta-regressions. J. Clin. Med. 9 (7), 2244. doi:10.3390/ jcm9072244

Dimopoulos, G., de Mast, Q., Markou, N., Theodorakopoulou, M., Komnos, A., Mouktaroudi, M., et al. (2020). Favorable anakinra responses IN severe COVID-19 patients with secondary hemophagocytic lymphohistiocytosis. Cell Host Microbe 28, 117-123. doi:10.1016/j.chom.2020.05.007

Ding, C., Feng, X., Chen, Y., Yuan, J., Yi, P., Li, Y., et al. (2020). Effect of corticosteroid therapy on the duration of SARS-CoV-2 clearance in patients with mild COVID-19: a retrospective cohort study. Infect. Dis. Ther. 9, 943-952. doi:10.1007/s40121-020-00337-y

Ding, Q., Lu, P., Fan, Y., Xia, Y., and Liu, M. (2020). The clinical characteristics of pneumonia patients coinfected with 2019 novel coronavirus and influenza virus in Wuhan, China. J. Med. Virol. 92, 1549-1555. doi:10.1002/jmv.25781

Diurno, F., Numis, F. G., Porta, G., Cirillo, F., Maddaluno, S., Ragozzino, A., et al. (2020). Eculizumab treatment in patients with COVID-19: preliminary results from real life ASL Napoli 2 Nord experience. Eur. Rev. Med. Pharmacol. Sci. 24 (7), 4040-4047. doi:10.26355/eurrev_202004_20875

Dofferhoff, A. S. M., Piscaer, I., Schurgers, L. J., Visser, M. P. J., van den Ouweland, J. M. W., de Jong, P. A., et al. (2020). Reduced vitamin K status as a potentially modifiable risk factor of severe COVID-19. Clin. Infect. Dis. 2020, ciaa1258. doi:10.1093/cid/ciaa1258

Doi, Y., Hibino, M., Hase, R., Yamamoto, M., Kasamatsu, Y., Hirose, M., et al. (2020). A prospective, randomized, open-label trial of early versus late favipiravir in hospitalized patients with COVID-19. Antimicrob. Agents Chemother. 64, e01897. doi:10.1128/aac.01897-20

Duan, K., Liu, B., Li, C., Zhang, H., Yu, T., Qu, J., et al. (2020a). Effectiveness of convalescent plasma therapy in severe COVID-19 patients. Proc. Natl. Acad. Sci. U. S. A. 117 (17), 9490-9496. doi:10.1073/pnas.2004168117

Duan, K., Liu, B., Li, C., Zhang, H., Yu, T., Qu, J., et al. (2020b). The feasibility of convalescent plasma therapy in severe COVID-19 patients: a pilot study. Available at: https://www.medrxiv.org/content/10.1101/2020.03.16.20036145v1.

Ekins, S., and Madrid, P. B. (2020). Tilorone, a broad-spectrum antiviral for emerging viruses. Antimicrob. Agents Chemother. 64 (5), e00440. doi:10.1128/ aac.00440-20

Elfiky, A. A. (2020a). Ribavirin, remdesivir, sofosbuvir, Galidesivir, and tenofovir against SARS-CoV-2 RNA dependent RNA polymerase (RdRp): a molecular docking study. Life Sci. 253, 117592. doi:10.1016/j.lfs.2020.117592

Elfiky, A. A. (2020b). SARS-CoV-2 RNA dependent RNA polymerase (RdRp) targeting: an in silico perspective. J. Biomol. Struct. Dyn. 2020, 1-9. doi:10.1080/ 07391102.2020 .1761882

Fadel, R., Morrison, A., Vahia, A., Smith, Z. R., Chaudhry, Z., Bhargava, P., et al. (2020). Early short course corticosteroids in hospitalized patients with COVID 19. Available at: https://www.medrxiv.org/content/10.1101/2020.05.04.20074609v1. 
Fan, J., Luo, J., Zhao, D., Deng, T., Weng, Y., Sun, Y., et al. (2020). A preliminary study on the reproductive toxicity of GS-5374 on the male mice. bioRxiv. 4 (21), 050104. doi:10.1101/2020.04.21.050104

Fang, J., Li, H., Du, W., Yu, P., Guan, Y. Y., Ma, S. Y., et al. (2020). Efficacy of early combination therapy with lianhuaqingwen and arbidol in moderate and severe COVID-19 patients: a retrospective cohort study. Front. Pharmacol. 11, 560209. doi:10.3389/fphar.2020.560209

Ferguson, J., Volk, S., Vondracek, T., Flanigan, J., and Chernaik, A. (2020). Empiric therapeutic anticoagulation and mortality in critically ill patients with respiratory failure from SARS-CoV-2: a retrospective cohort study. J. Clin. Pharmacol. 60 (11), 1411-1415. doi:10.1002/jcph.1749

Ferner, R. E., and Aronson, J. K. (2020). Chloroquine and hydroxychloroquine in covid-19. Br. Med. J. 369, m1432. doi:10.1136/bmj.m1432

Foss, F. M., Rubinowitz, A., Landry, M. L., Isufi, I., Gowda, L., Seropian, S., et al. (2020). Attenuated novel SARS coronavirus 2 infection in an allogeneic hematopoietic stem cell transplant patient on Ruxolitinib. Clin. Lymphoma Myeloma Leuk. 20 (11), 720-723. doi:10.1016/j.clml.2020.06.014

Fu, D., Cao, R., Zhao, L., Li, W., Zhong, W., and Wen, J. (2020). Oral favipiravir for patients with delayed SARS-CoV-2 viral RNA clearance: a case series. Crit. Care 24 (1), 578. doi:10.1186/s13054-020-03288-5

Fukao, K., Ando, Y., Noshi, T., Kitano, M., Noda, T., Kawai, M., et al. (2019). Baloxavir marboxil, a novel cap-dependent endonuclease inhibitor potently suppresses influenza virus replication and represents therapeutic effects in both immunocompetent and immunocompromised mouse models. PloS One 14 (5), e0217307. doi:10.1371/journal.pone.0217307

Gautret, P., Lagier, J.-C., Parola, P., Hoang, V. T., Meddeb, L., Mailhe, M., et al. (2020a). Hydroxychloroquine and azithromycin as a treatment of COVID-19: results of an open-label non-randomized clinical trial. Int. J. Antimicrob. Agents 56, 105949. doi:10.1016/j.ijantimicag.2020.105949

Gautret, P., Lagier, J. C., Parola, P., Hoang, V. T., Meddeb, L., Sevestre, J., et al. (2020b). Clinical and microbiological effect of a combination of hydroxychloroquine and azithromycin in 80 COVID-19 patients with at least a six-day follow up: a pilot observational study. Trav. Med. Infect. Dis. 34, 101663. doi:10.1016/j.tmaid.2020.101663

Ge, Y., Tian, T., Huang, S., Wan, F., Li, J., Li, S., et al. (2020). A data-driven drug repositioning framework discovered a potential therapeutic agent targeting COVID-19. Available at: https://www.biorxiv.org/content/10.1101/2020.03.11. 986836v1.

Geleris, J., Sun, Y., Platt, J., Zucker, J., Baldwin, M., Hripcsak, G., et al. (2020). Observational study of hydroxychloroquine in hospitalized patients with covid19. N. Engl. J. Med. 382 (25), 2411-2418. doi:10.1056/NEJMoa2012410

Gemici, A., Bilgen, H., ErdoĞan, C., Kansu, A., OlmuŞÇeli̇k, O., BekÖz, H. S., et al. (2020). A single center cohort of 40 severe COVID-19 patients who were treated with convalescent plasma. Turk. J. Med. Sci. 50, 1781-1785. doi:10.3906/sag2009-77

Gentile, P., and Sterodimas, A. (2020). Adipose-derived stromal stem cells (ASCs) as a new regenerative immediate therapy combating coronavirus (COVID-19)Induced pneumonia. Expet Opin. Biol. Ther. 20, 711-716. doi:10.1080/ 14712598.2020.1761322

Gharebaghi, R., Heidary, F., Moradi, M., and Parvizi, M. (2020). Metronidazole; a potential novel addition to the COVID-19 treatment regimen. Arch Acad Emerg Med. 8 (1), e40. doi:10.2139/ssrn. 3559020

Giamarellos-Bourboulis, E. J., Netea, M. G., Rovina, N., Akinosoglou, K., Antoniadou, A., Antonakos, N., et al. (2020). Complex immune dysregulation in COVID-19 patients with severe respiratory failure. Cell Host Microbe 27 (6), 992-1000. doi:10.1016/j.chom.2020.04.009

Goldman, J. D., Lye, D. C. B., Hui, D. S., Marks, K. M., Bruno, R., Montejano, R., et al. (2020). Remdesivir for 5 or 10 Days in patients with severe covid-19. N. Engl. J. Med. 383, 1827-1837. doi:10.1056/NEJMoa2015301

Goodman, A. D., Anadani, N., and Gerwitz, L. (2019). Siponimod in the treatment of multiple sclerosis. Expet Opin. Invest. Drugs 28 (12), 1051-1057. doi:10.1080/ 13543784.2019.1676725

Gorial, F. I., Mashhadani, S., Sayaly, H. M., Dakhil, B. D., AlMashhadani, M. M., Aljabory, A. M., et al. (2020). Effectiveness of ivermectin as add-on therapy in COVID-19 management (pilot trial). medRxiv 2020, 20145979. doi:10.1101/ 2020.07.07.20145979

Grant, W. B., Lahore, H., McDonnell, S. L., Baggerly, C. A., French, C. B., Aliano, J. L., et al. (2020). Evidence that vitamin D supplementation could reduce risk of influenza and COVID-19 infections and deaths. Nutrients 12 (4), 988. doi:10. 3390/nu12040988

Grein, J., Ohmagari, N., Shin, D., Diaz, G., Asperges, E., Castagna, A., et al. (2020). Compassionate use of remdesivir for patients with severe covid-19. N. Engl. J. Med. 382, 2327-2336. doi:10.1056/NEJMoa2007016

Gui, M., Song, W., Zhou, H., Xu, J., Chen, S., Xiang, Y., et al. (2017). Cryo-electron microscopy structures of the SARS-CoV spike glycoprotein reveal a prerequisite conformational state for receptor binding. Cell Res. 27 (1), 119-129. doi:10. $1038 /$ cr.2016.152

Guo, Q., Li, M., Wang, C., Wang, P., Fang, Z., Tan, J., et al. (2020). Host and infectivity prediction of Wuhan 2019 novel coronavirus using deep learning algorithm. bioRxiv 2001, 2021. doi:10.1101/2020.01.21.914044

Guzik, T. J., Mohiddin, S. A., Dimarco, A., Patel, V., Savvatis, K., Marelli-Berg, F. M., et al. (2020). COVID-19 and the cardiovascular system: implications for risk assessment, diagnosis, and treatment options. Cardiovasc. Res. 116 (10), 1666-1687. doi:10.1093/cvr/cvaa106

Hadjadj, J., Yatim, N., Barnabei, L., Corneau, A., Boussier, J., Pere, H., et al. (2020). Impaired type I interferon activity and exacerbated inflammatory responses in severe Covid-19 patients. Available at: https://www.medrxiv.org/content/10. 1101/2020.04.19.20068015v1.

Han, W., Quan, B., Guo, Y., Zhang, J., Lu, Y., Feng, G., et al. (2020). The course of clinical diagnosis and treatment of a case infected with coronavirus disease 2019. J. Med. Virol. 92 (5), 461-463. doi:10.1002/jmv.25711

Haque, S., Jawed, A., Akhter, N., Dar, S. A., Khan, F., Mandal, R. K., et al. (2020). Acetylsalicylic acid (Aspirin): a potent medicine for preventing COVID-19 deaths caused by thrombosis and pulmonary embolism. Eur. Rev. Med. Pharmacol. Sci. 24 (18), 9244-9245. doi:10.26355/eurrev_202009_23005

Harley, C. A., Dasgupta, A., and Wilson, D. W. (2001). Characterization of herpes simplex virus-containing organelles by subcellular fractionation: role for organelle acidification in assembly of infectious particles. J. Virol. 75 (3), 1236-1251. doi:10.1128/jvi.75.3.1236-1251.2001

Hashem, A. M., Alghamdi, B. S., Algaissi, A. A., Alshehri, F. S., Bukhari, A., Alfaleh, M. A., et al. (2020). Therapeutic use of chloroquine and hydroxychloroquine in COVID-19 and other viral infections: a narrative review. Trav. Med. Infect. Dis. 35, 101735. doi:10.1016/j.tmaid.2020.101735

Hemilä, H. (2003). Vitamin C and SARS coronavirus. J. Antimicrob. Chemother. 52 (6), 1049-1050. doi:10.1093/jac/dkh002

Hemilä, H. (1997). Vitamin C intake and susceptibility to pneumonia. Pediatr. Infect. Dis. J. 16 (9), 836-837. doi:10.1097/00006454-199709000-00003

Hoffmann, M., Kleine-Weber, H., Schroeder, S., Kruger, N., Herrler, T., Erichsen, S., et al. (2020). SARS-CoV-2 cell entry depends on ACE2 and TMPRSS2 and is blocked by a clinically proven protease inhibitor. Cell 181 (2), 271-280. doi:10. 1016/j.cell.2020.02.052

Holshue, M. L., DeBolt, C., Lindquist, S., Lofy, K. H., Wiesman, J., Bruce, H., et al. (2020). First case of 2019 novel coronavirus in the United States. N. Engl. J. Med. 382 (10), 929-936. doi:10.1056/NEJMoa2001191

Hsu, C.-Y., Lai, C.-C., Yen, A. M.-F., Chen, S. L.-S., and Chen, H.-H. (2020). Efficacy of remdesivir in COVID-19 patients with a simulated two-arm controlled study. Available at: https://pesquisa.bvsalud.org/global-literatureon-novel-coronavirus-2019-ncov/resource/en/ppmedrxiv-20088559.

Huang, C., Wang, Y., Li, X., Ren, L., Zhao, J., Hu, Y., et al. (2020). Clinical features of patients infected with 2019 novel coronavirus in Wuhan, China. Lancet 395 (10223), 497-506. doi:10.1016/s0140-6736(20)30183-5

Huang, J., Song, W., Huang, H., and Sun, Q. (2020). Pharmacological therapeutics targeting RNA-dependent RNA polymerase, proteinase and spike protein: from mechanistic studies to clinical trials for COVID-19. J. Clin. Med. 9 (4), 1131. doi: $10.3390 / \mathrm{jcm} 9041131$

Huang, L., Shi, Y., Gong, B., Jiang, L., Liu, X., Yang, J., et al. (2020). Blood single cell immune profiling reveals the interferon-MAPK pathway mediated adaptive immune response for COVID-19. medRxiv 2020, 20033472. doi:10.1101/2020. 03.15.20033472

Huang, M., Tang, T., Pang, P., Li, M., Ma, R., Lu, J., et al. (2020). Treating COVID19 with chloroquine. J. Mol. Cell Biol. 12, 322-325. doi:10.1093/jmcb/mjaa014

Hung, I. F., Lung, K. C., Tso, E. Y., Liu, R., Chung, T. W., Chu, M. Y., et al. (2020). Triple combination of interferon beta- $1 \mathrm{~b}$, lopinavir-ritonavir, and ribavirin in the treatment of patients admitted to hospital with COVID-19: an open-label, randomised, phase 2 trial. Lancet 395, 1695-1704. doi:10.1016/s0140-6736(20) $31042-4$ 
Huwiler, A., and Zangemeister-Wittke, U. (2018). The sphingosine 1-phosphate receptor modulator fingolimod as a therapeutic agent: recent findings and new perspectives. Pharmacol. Ther. 185, 34-49. doi:10.1016/j.pharmthera.2017. 11.001

Instruction of Tocilizumab (2020). Actemra. Available at: https://www.gene.com/ download/pdf/actemra_prescribing.pdf.

Jacobs, M., Rodger, A., Bell, D. J., Bhagani, S., Cropley, I., Filipe, A., et al. (2016). Late Ebola virus relapse causing meningoencephalitis: a case report. Lancet 388 (10043), 498-503. doi:10.1016/s0140-6736(16)30386-5

Jeon, S., Ko, M., Lee, J., Choi, I., Byun, S. Y., Park, S., et al. (2020). Identification of antiviral drug candidates against SARS-CoV-2 from FDA-approved drugs. Available at: https://www.biorxiv.org/content/10.1101/2020.03.20.999730v1.

Jeronimo, C. M. P., Farias, M. E. L., Val, F. F. A., Sampaio, V. S., Alexandre, M. A. A., Melo, G. C., et al. (2020). Methylprednisolone as adjunctive therapy for patients hospitalized with COVID-19 (metcovid): a randomised, double-blind, phase IIb, placebo-controlled trial. Clin. Infect. Dis. 12, ciaal177. doi:10.1093/ $\mathrm{cid} / \mathrm{ciaa} 1177$

Ji, W., Wang, W., Zhao, X., Zai, J., and Li, X. (2020). Cross-species transmission of the newly identified coronavirus 2019-nCoV. J. Med. Virol. 92 (4), 433-440. doi:10.1002/jmv. 25682

Jin, C. C., Zhu, L., Gao, C., and Zhang, S. (2020). Correlation between viral RNA shedding and serum antibodies in individuals with coronavirus disease 2019. Clin. Microbiol. Infect. 26 (9), 1280-1282. doi:10.1016/j.cmi.2020.05.022

Joyner, M., Wright, R. S., Fairweather, D., Senefeld, J., Bruno, K., Klassen, S., et al. (2020). Early safety indicators of COVID-19 convalescent plasma in 5,000 patients. Available at: https://www.medrxiv.org/content/10.1101/2020.05.12. 20099879v1.

Ju, J., Kumar, S., Li, X., Jockusch, S., and Russo, J. J. (2020). Nucleotide analogues as inhibitors of viral polymerases. Available at: https://www.biorxiv.org/content/ 10.1101/2020.01.30.927574v1.

Julander, J. G., Siddharthan, V., Evans, J., Taylor, R., Tolbert, K., Apuli, C., et al. (2017). Efficacy of the broad-spectrum antiviral compound BCX4430 against Zika virus in cell culture and in a mouse model. Antivir. Res. 137, 14-22. doi:10. 1016/j.antiviral.2016.11.003

Kadam, R. U., and Wilson, I. A. (2017). Structural basis of influenza virus fusion inhibition by the antiviral drug Arbidol. Proc. Natl. Acad. Sci. Unit. States Am. 114 (2), 206. doi:10.1073/pnas.1617020114

Kang, S., Peng, W., Zhu, Y., Lu, S., Zhou, M., Lin, W., et al. (2020). Recent progress in understanding 2019 novel coronavirus (SARS-CoV-2) associated with human respiratory disease: detection, mechanisms and treatment. Int. J. Antimicrob. Agents 55 (5), 105950. doi:10.1016/j.ijantimicag.2020.105950

Kassi, E. N., Papavassiliou, K. A., and Papavassiliou, A. G. (2020). G6PD and chloroquine: selecting the treatment against SARS-CoV-2? J. Cell Mol. Med. 24, 4913-4914. doi:10.1111/jcmm.15312

Khoury, M., Cuenca, J., Cruz, F. F., Figueroa, F. E., Rocco, P. R. M., and Weiss, D. J. (2020). Current status of cell-based therapies for respiratory virus infections: applicability to COVID-19. Eur. Respir. J. 55, 2000858. doi:10.1183/13993003. 00858-2020

Klasse, P. J. (2014). Neutralization of virus infectivity by antibodies: old problems in new perspectives. Adv. Biol. 2014, 157895. doi:10.1155/2014/157895

Ko, W.-C., Rolain, J.-M., Lee, N.-Y., Chen, P.-L., Huang, C.-T., Lee, P.-I., et al. (2020). Arguments in favour of remdesivir for treating SARS-CoV-2 infections. Int. J. Antimicrob. Agents 55 (4), 105933. doi:10.1016/j.ijantimicag.2020.105933

Kwiek, J. J., Haystead, T. A., and Rudolph, J. (2004). Kinetic mechanism of quinone oxidoreductase 2 and its inhibition by the antimalarial quinolines. Biochemistry 43 (15), 4538-4547. doi:10.1021/bi035923w

Lan, J., Ge, J., Yu, J., Shan, S., Zhou, H., Fan, S., et al. (2020). Structure of the SARSCoV-2 spike receptor-binding domain bound to the ACE2 receptor. Nature 581 (7807), 215-220. doi:10.1038/s41586-020-2180-5

Lê, M. P., Jaquet, P., Patrier, J., Wicky, P. H., Le Hingrat, Q., Veyrier, M., et al. (2020). Pharmacokinetics of lopinavir/ritonavir oral solution to treat COVID19 in mechanically ventilated ICU patients. J. Antimicrob. Chemother. 75 (9), 2657-2660. doi:10.1093/jac/dkaa261

Lechien, J. R., Chiesa-Estomba, C. M., De Siati, D. R., Horoi, M., Le Bon, S. D., Rodriguez, A., et al. (2020). Olfactory and gustatory dysfunctions as a clinical presentation of mild-to-moderate forms of the coronavirus disease (COVID19): a multicenter European study. Eur. Arch. Oto-Rhino-Laryngol. 277, 2251-2261. doi:10.1007/s00405-020-05965-1
Lecuit, M. (2020). Chloroquine and COVID-19, where do we stand? Med. Maladies Infect. 50, 229-230. doi:10.1016/j.medmal.2020.03.004

Lee, H. K., Jung, O., and Hennighausen, L. (2020). Activation of ACE2 and interferon-stimulated transcriptomes in human airway epithelium is curbed by Janus Kinase inhibitors. Available at: https://www.biorxiv.org/content/10.1101/ 2020.10.04.325415v1.

Leng, Z., Zhu, R., Hou, W., Feng, Y., Yang, Y., Han, Q., et al. (2020). Transplantation of ACE2 mesenchymal stem cells improves the outcome of patients with COVID-19 pneumonia. Aging and disease 11 (2), 216-228. doi:10. 14336/AD.2020.0228

Lentini, G., Cavalluzzi, M. M., and Habtemariam, S. (2020). COVID-19, chloroquine repurposing, and cardiac safety concern: chirality might help. Molecules 25 (8), 1834. doi:10.3390/molecules25081834

Levy, C., Lassailly, G., Parmentier, E., Duburcq, T., Mathurin, P., and Poissy, J. (2020). Caution with the use of lopinavir/ritonavir in severely ill patients for the treatment of SARS-CoV-2: a report of severe jaundice. Am. J. Gastroenterol. 115 (10), 1716-1718. doi:10.14309/ajg.0000000000000828

Li, D., Gong, R., Zheng, J., Chen, X., Dimitrov, D. S., and Zhao, Q. (2017). Engineered antibody $\mathrm{CH} 2$ domains binding to nucleolin: isolation, characterization and improvement of aggregation. Biochem. Biophys. Res. Commun. 485 (2), 446-453. doi:10.1016/j.bbrc.2017.02.058

Li, L., Zhang, W., Hu, Y., Tong, X., Zheng, S., Yang, J., et al. (2020). Effect of convalescent plasma therapy on time to clinical improvement in patients with severe and life-threatening COVID-19: a randomized clinical trial. Jama 324, 460-470. doi:10.1001/jama.2020.10044

Li, Q., Guan, X., Wu, P., Wang, X., Zhou, L., Tong, Y., et al. (2020). Early transmission dynamics in Wuhan, China, of novel coronavirus-infected pneumonia. N. Engl. J. Med. 382 (13), 1199-1207. doi:10.1056/ nejmoa2001316

Li, W., Shi, Z., Yu, M., Ren, W., Smith, C., Epstein, J. H., et al. (2005). Bats are natural reservoirs of SARS-like coronaviruses. Science 310 (5748), 676-679. doi:10.1126/science.1118391

Li, X., Geng, M., Peng, Y., Meng, L., and Lu, S. (2020). Molecular immune pathogenesis and diagnosis of COVID-19. J. Pharm. Anal. 10 (2), 102-108. doi:10.1016/j.jpha.2020.03.001

Li, Y., Xie, Z., Lin, W., Cai, W., Wen, C., Guan, Y., et al. (2020a). An exploratory randomized controlled study on the efficacy and safety of lopinavir/ritonavir or arbidol treating adult patients hospitalized with mild/moderate COVID-19 (ELACOI). Available at: https://www.medrxiv.org/content/10.1101/2020.03.19. $20038984 \mathrm{v} 2$.

Li, Y., Xie, Z., Lin, W., Cai, W., Wen, C., Guan, Y., et al. (2020b). Efficacy and safety of lopinavir/ritonavir or arbidol in adult patients with mild/moderate COVID19: an exploratory randomized controlled trial. Med. 1, 105-113. doi:10.1016/j. medj.2020.04.001

Lian, N., Xie, H., Lin, S., Huang, J., Zhao, J., and Lin, Q. (2020). Umifenovir treatment is not associated with improved outcomes in patients with coronavirus disease 2019: a retrospective study. Clin. Microbiol. Infect. 26 (7), 917-921. doi:10.1016/j.cmi.2020.04.026

Liao, D., Zhou, F., Luo, L., Xu, M., Wang, H., Xia, J., et al. (2020). Haematological characteristics and risk factors in the classification and prognosis evaluation of COVID-19: a retrospective cohort study. Lancet Haematol 7 (9), e671-e678. doi:10.1016/S2352-3026(20)30217-9

Lim, J., Jeon, S., Shin, H.-Y., Kim, M. J., Seong, Y. M., Lee, W. J., et al. (2020). Case of the index patient who caused tertiary transmission of coronavirus disease 2019 in korea: the application of lopinavir/ritonavir for the treatment of COVID-19 pneumonia monitored by quantitative RT-PCR. J. Kor. Med. Sci. 35 (6), e79. doi:10.3346/jkms.2020.35.e79

Liu, X., Li, Z., Liu, S., Chen, Z., Zhao, Z., Huang, Y.-Y., et al. (2020). Therapeutic effects of dipyridamole on COVID-19 patients with coagulation dysfunction. Available at: https://www.medrxiv.org/content/10.1101/2020.02.27.20027557v1. full.

Lo, M. K., Jordan, R., Arvey, A., Sudhamsu, J., Shrivastava-Ranjan, P., Hotard, A. L., et al. (2017). GS-5734 and its parent nucleoside analog inhibit filo-, pneumo-, and paramyxoviruses. Sci. Rep. 7, 43395. doi:10.1038/srep43395

Lou, Y., Liu, L., Yao, H., Hu, X., Su, J., Xu, K., et al. (2020). Clinical outcomes and plasma concentrations of baloxavir marboxil and favipiravir in COVID-19 patients: an exploratory randomized, controlled trial. Eur. J. Pharmaceut. Sci. 157, 105631. doi:10.1016/j.ejps.2020.105631 
Lu, X., Chen, T., Wang, Y., Wang, J., Zhang, B., Li, Y., et al. (2020). Adjuvant corticosteroid therapy for critically ill patients with COVID-19. Available at: https://www.medrxiv.org/content/10.1101/2020.04.07.20056390v1.

Luo, H., Li, Q., Flower, A, Lewith, G., and Liu, J. (2012). Comparison of effectiveness and safety between granules and decoction of Chinese herbal medicine: a systematic review of randomized clinical trials. J. Ethnopharm. 140, 555-567. doi:10.1016/j.jep.2012.01.031

Lv, C., Liu, W., Wang, B., Dang, R., Qiu, L., Ren, J., et al. (2018). Ivermectin inhibits DNA polymerase UL42 of pseudorabies virus entrance into the nucleus and proliferation of the virus in vitro and vivo. Antivir. Res. 159, 55-62. doi:10.1016/ j.antiviral.2018.09.010

Lyu Ruibing, W. W., and Li, X. (2020). Traditional Chinese medicine lianhua qingwen treating 63 suspected cases with new coronavirus pneumonia: clinical observations. Available at: http://kns.cnki.net/kcms/detail/11.2166.R.20200215. 1633.004.html.

Maatman, T. K., Jalali, F., Feizpour, C., Douglas, A., II, McGuire, S. P., Kinnaman, G., et al. (2020). Routine venous thromboembolism prophylaxis may Be inadequate in the hypercoagulable state of severe coronavirus disease 2019. Crit. Care Med. 48 (9), e783-e790. doi:10.1097/ccm.0000000000004466

Madariaga, M. L. L., Guthmiller, J. J., Schrantz, S., Jansen, M. O., Christensen, C., Kumar, M., et al. (2020). Clinical predictors of donor antibody titer and correlation with recipient antibody response in a COVID-19 convalescent plasma clinical trial. J. Intern. Med. doi:10.1111/joim.13185

Magagnoli, J., Narendran, S., Pereira, F., Cummings, T., Hardin, J. W., Sutton, S. S., et al. (2020). Outcomes of hydroxychloroquine usage in United States veterans hospitalized with Covid-19. Available at: https://www.medrxiv.org/content/10. 1101/2020.04.16.20065920v2.

Mahévas, M., Tran, V. T., Roumier, M., Chabrol, A., Paule, R., Guillaud, C., et al. (2020). Clinical efficacy of hydroxychloroquine in patients with covid-19 pneumonia who require oxygen: observational comparative study using routine care data. Br. Med. J. 369, m1844. doi:10.1136/bmj.m1844

Malekzadeh, R., Abedini, A., Mohsenpour, B., Sharifipour, E., Ghasemian, R., Javad-Mousavi, S. A., et al. (2020). Subcutaneous tocilizumab in adults with severe and critical COVID-19: a prospective open-label uncontrolled multicenter trial. Int. Immunopharm. 89 (Pt B), 107102. doi:10.1016/j. intimp.2020.107102

Marmor, M. F. (2020). COVID-19 and chloroquine/hydroxychloroquine: is there ophthalmological concern? Am. J. Ophthalmol. 68, 683-687. doi:10.1016/j.ajo. 2020.03.028

Mastrangelo, E., Pezzullo, M., De Burghgraeve, T., Kaptein, S., Pastorino, B., Dallmeier, K., et al. (2012). Ivermectin is a potent inhibitor of flavivirus replication specifically targeting NS3 helicase activity: new prospects for an old drug. J. Antimicrob. Chemother. 67 (8), 1884-1894. doi:10.1093/jac/dks147

McGuire, L. W., and Redden, W. R. (1918). The use of convalescent human serum IN influenza pneumonia-a preliminary report. Am J Public Health 8, 741-744. doi:10.2105/ajph.8.10.741

McInnes, I. B., Byers, N. L., Higgs, R. E., Lee, J., Macias, W. L., Na, S., et al. (2019). Comparison of baricitinib, upadacitinib, and tofacitinib mediated regulation of cytokine signaling in human leukocyte subpopulations. Arthritis Res. Ther. 21 (1), 183. doi:10.1186/s13075-019-1964-1

Meng, F., Xu, R., Wang, S., Xu, Z., Zhang, C., Li, Y., et al. (2020). Human umbilical cord-derived mesenchymal stem cell therapy in patients with COVID-19: a phase 1 clinical trial. Signal Transduct Target Ther 5 (1), 172. doi:10.1038/ s41392-020-00286-5

Mercuro, N. J., Yen, C. F., Shim, D. J., Maher, T. R., McCoy, C. M., Zimetbaum, P. J., et al. (2020). Risk of QT interval prolongation associated with use of hydroxychloroquine with or without concomitant azithromycin among hospitalized patients testing positive for coronavirus disease 2019 (COVID19). JAMA Cardiol. 5 (9), 1036-1041. doi:10.1001/jamacardio.2020.1834

Merzon, E., Tworowski, D., Gorohovski, A., Vinker, S., Golan Cohen, A., Green, I., et al. (2020). Low plasma 25(OH) vitamin D level is associated with increased risk of COVID-19 infection: an Israeli population-based study. FEBS J. 287, 3693-3702. doi:10.1111/febs.15495

Metcalfe, S. M. (2020). Mesenchymal stem cells and management of COVID-19 pneumonia. Med. Drug Discovery 5, 100019. doi:10.1016/j.medidd.2020. 100019

Michot, J. M., Albiges, L., Chaput, N., Saada, V., Pommeret, F., Griscelli, F., et al. (2020). Tocilizumab, an anti-IL6 receptor antibody, to treat Covid-19-related respiratory failure: a case report. Ann. Oncol. 31, 961-964. doi:10.1016/j. annonc.2020.03.300

Misra, D. P., Agarwal, V., Gasparyan, A. Y., and Zimba, O. (2020). Rheumatologists' perspective on coronavirus disease 19 (COVID-19) and potential therapeutic targets. Clin. Rheumatol. 39, 2055-2062. doi:10.1007/ s10067-020-05073-9

Mitja, O., Ubals, M., Corbacho, M., Alemany, A., Suner, C., Tebe, C., et al. (2020). A cluster-randomized trial of hydroxychloroquine as prevention of covid-19 transmission and disease. medRxiv 2007, 20157651. doi:10.1101/2020.07.20. 20157651

Mitoma, H., Horiuchi, T., Tsukamoto, H., and Ueda, N. (2018). Molecular mechanisms of action of anti-TNF- $\alpha$ agents - comparison among therapeutic TNF- $\alpha$ antagonists. Cytokine 101, 56-63. doi:10.1016/j.cyto.2016. 08.014

Mittal, L., Kumari, A., Srivastava, M., Singh, M., and Asthana, S. (2020). Identification of potential molecules against COVID-19 main protease through structure-guided virtual screening approach. J. Biomol. Struct. Dyn. 2020, 1-26. doi:10.1080/07391102.2020.1768151

Monreal, E., Sainz de la Maza, S., Natera-Villalba, E., Beltran-Corbellini, A., Rodriguez-Jorge, F., Fernandez-Velasco, J. I., et al. (2020). High versus standard doses of corticosteroids in severe COVID-19: a retrospective cohort study. Eur. J. Clin. Microbiol. Infect. Dis. 2020, 1-9. doi:10.1007/ s10096-020-04078-1

Morrison, A. R., Johnson, J. M., Ramesh, M., Bradley, P., Jennings, J., and Smith, Z. R. (2020). Letter to the Editor: acute hypertriglyceridemia in patients with COVID-19 receiving tocilizumab. J. Med. Virol. 92, 1791-1792. doi:10.1002/ jmv. 25907

Mullard, A. (2018). Ebola outbreak prompts experimental drug rollout. Nat. Rev. Drug Discov. 17 (7), 460. doi:10.1038/nrd.2018.114

Musarrat, F., Chouljenko, V., Dahal, A., Nabi, R., Chouljenko, T., Jois, S. D., et al. (2020). The anti-HIV drug nelfinavir mesylate (viracept) is a potent inhibitor of cell fusion caused by the SARS-CoV-2 spike (S) glycoprotein warranting further evaluation as an antiviral against COVID-19 infections. J. Med. Virol. 92, 2087-2095. doi:10.1002/jmv.25985

National Administration of Traditional Chinese Medicine (2020). Progress in screening of effective prescriptions of traditional Chinese medicine. Available at: http://bgs.satcm.gov.cn/gongzuodongtai/2020-02-06/12866.html.

Ni, L., Zhou, L., Zhou, M., Zhao, J., and Wang, D. W. (2020). Combination of western medicine and Chinese traditional patent medicine in treating a family case of COVID-19 in Wuhan. Front. Med. 14 (2), 210-214. doi:10.1007/s11684020-0757-x

Nicolai, L., Leunig, A., Brambs, S., Kaiser, R., Weinberger, T., Weigand, M., et al. (2020). Immunothrombotic dysregulation in COVID-19 pneumonia is associated with respiratory failure and coagulopathy. Circulation 142 (12), 1176-1189. doi:10.1161/circulationaha.120.048488

Novel, C. P. E. R. E. (2020). [The epidemiological characteristics of an outbreak of 2019 novel coronavirus diseases (COVID-19) in China]. Zhonghua Liu Xing Bing Xue Za Zhi 41, 145-151. doi:10.3760/cma.j.issn.0254-6450.2020.02.003

Nutho, B., Mahalapbutr, P., Hengphasatporn, K., Pattaranggoon, N. C., Simanon, N., Shigeta, Y., et al. (2020). Why are lopinavir and ritonavir effective against the newly emerged coronavirus 2019? Atomistic insights into the inhibitory mechanisms. Biochemistry 59 (18), 1769-1779. doi:10.1021/acs.biochem. 0c00160

Ohashi, H., Watashi, K., Saso, W., Shionoya, K., Iwanami, S., Hirokawa, T., et al. (2020). Multidrug treatment with nelfinavir and cepharanthine against COVID-19. Available at: https://www.biorxiv.org/content/10.1101/2020.04. $14.039925 \mathrm{v} 1$.

Olender, S. A., Perez, K. K., Go, A. S., Balani, B., Price-Haywood, E. G., Shah, N. S., et al. (2020). Remdesivir for severe COVID-19 versus a cohort receiving standard of care. Clin. Infect. Dis. 24, ciaa1041. doi:10.1093/cid/ciaa1041

Omrani, A. S., Saad, M. M., Baig, K., Bahloul, A., Abdul-Matin, M., Alaidaroos, A. Y., et al. (2014). Ribavirin and interferon alfa-2a for severe Middle East respiratory syndrome coronavirus infection: a retrospective cohort study. Lancet Infect. Dis. 14 (11), 1090-1095. doi:10.1016/s1473-3099(14)70920-x

Pal, P., Ibrahim, M., Niu, A., Zwezdaryk, K. J., Tatje, E., Robinson, W. R. T., et al. (2020). Safety and efficacy of COVID-19 convalescent plasma in severe pulmonary disease: a report of 17 patients. Transfus. Med. 2020, 12729. doi:10.1111/tme.12729 
Palacio, N., Dangi, T., Chung, Y. R., Wang, Y., Loredo-Varela, J. L., Zhang, Z., et al. (2020). Early type I IFN blockade improves the efficacy of viral vaccines. J. Exp. Med. 217 (12), e20191220. doi:10.1084/jem.20191220

Pan, H., Peto, R., Karim, Q. A., Alejandria, M., Henao-Restrepo, A. M., et al. (2020). Repurposed antiviral drugs for COVID-19-interim WHO SOLIDARITY trial results. Houston, Texas: medRxiv.

Pantos, C., Tseti, I., and Mourouzis, I. (2020). Use of triiodothyronine to treat critically ill COVID-19 patients: a new clinical trial. Crit. Care 24 (1), 209. doi:10.1186/s13054-020-02934-2

Paranjpe, I., Fuster, V., Lala, A., Russak, A. J., Glicksberg, B. S., Levin, M. A., et al. (2020). Association of treatment dose anticoagulation with in-hospital survival among hospitalized patients with COVID-19. J. Am. Coll. Cardiol. 76 (1), 122-124. doi:10.1016/j.jacc.2020.05.001

Pasi, S., Kant, R., Gupta, S., and Surolia, A. (2015). Novel multimeric IL-1 receptor antagonist for the treatment of rheumatoid arthritis. Biomaterials 42, 121-133. doi:10.1016/j.biomaterials.2014.11.041

Pavoni, V., Gianesello, L., Pazzi, M., Stera, C., Meconi, T., and Frigieri, F. C. (2020). Venous thromboembolism and bleeding in critically ill COVID-19 patients treated with higher than standard low molecular weight heparin doses and aspirin: a call to action. Thromb. Res. 196, 313-317. doi:10.1016/j.thromres. 2020.09.013

Perrone, F., Piccirillo, M. C., Ascierto, P. A., Salvarani, C., Parrella, R., Marata, A. M., et al. (2020). Tocilizumab for patients with COVID-19 pneumonia. The single-arm TOCIVID-19 prospective trial. J. Transl. Med. 18 (1), 405. doi:10. 1186/s12967-020-02573-9

Piazza, G., Campia, U., Hurwitz, S., Snyder, J. E., Rizzo, S. M., Pfeferman, M. B., et al. (2020). Registry of arterial and venous thromboembolic complications in patients with COVID-19. J. Am. Coll. Cardiol. 76 (18), 2060-2072. doi:10.1016/ j.jacc.2020.08.070

Pindiprolu, S., and Pindiprolu, S. H. (2020). Plausible mechanisms of Niclosamide as an antiviral agent against COVID-19. Med. Hypotheses 140, 109765. doi:10. 1016/j.mehy.2020.109765

Poston, J. T., Patel, B. K., and Davis, A. M. (2020). Management of critically ill adults with COVID-19. Jama 323, 1839. doi:10.1001/jama.2020.4914

Praveen, D., Puvvada, R. C., and Vijey, A. (2020). Janus kinase inhibitor baricitinib is not an ideal option for management of COVID-19. Int. J. Antimicrob. Agents 55, 105967. doi:10.1016/j.ijantimicag.2020.105967

Prokunina-Olsson, L., Alphonse, N., Dickenson, R. E., Durbin, J. E., Glenn, J. S., Hartmann, R., et al. (2020). COVID-19 and emerging viral infections: the case for interferon lambda. J. Exp. Med. 217 (5), e20200653. doi:10.1084/jem. 20200653

Publicity Department of the People's Republic of China (2020). Press conference of the joint prevention and control mechanism of state council. Available at: http://www.nhc.gov.cn/xcs/fkdt/202002/f12a62d10c2a48c6895cedf2faea6elf. shtml.

Qiu, R., Zhao, C., Liang, T., Hao, X., Huang, Y., Zhang, X., et al. (2020). Core outcome set for clinical trials of COVID-19 based on traditional Chinese and western medicine. Houston, Texas: medRxiv.

Radujkovic, A., Hippchen, T., Tiwari-Heckler, S., Dreher, S., Boxberger, M., and Merle, U. (2020). Vitamin D deficiency and outcome of COVID-19 patients. Nutrients 12 (9), 2757. doi:10.3390/nu12092757

Rajter, J. C., Sherman, M. S., Fatteh, N., Vogel, F., Sacks, J., and Rajter, J. J. (2020). Use of ivermectin is associated with lower mortality in hospitalized patients with COVID-19 (ICON study). Chest 159, 85-92. doi:10.1016/j.chest.2020. 10.009

Ramaswamy, M., Mannam, P., Comer, R., Sinclair, E., McQuaid, D. B., and Schmidt, M. L. (2020). Off-label real world experience using tocilizumab for patients hospitalized with COVID-19 disease in a regional community health system: a case-control study. Houston, Texas: medRxiv.

RECOVERY Collaborative Group (2020). Lopinavir-ritonavir in patients admitted to hospital with COVID-19 (RECOVERY): a randomised, controlled, openlabel, platform trial. Lancet 396 (10259), 1345-1352. doi:10.1016/s01406736(20)32013-4

Richardson, P., Griffin, I., Tucker, C., Smith, D., Oechsle, O., Phelan, A., et al. (2020). Baricitinib as potential treatment for $2019-\mathrm{nCoV}$ acute respiratory disease. Lancet 395 (10223), e30-e31. doi:10.1016/s0140-6736(20)30304-4

Rimland, C. A., Morgan, C. E., Bell, G. J., Kim, M. K., Hedrick, T., Marx, A., et al. (2020). Clinical characteristics and early outcomes in patients with COVID-19 treated with tocilizumab at a United States academic center. Houston, Texas: medRxiv.

Rogers, R., Shehadeh, F., Mylona, E. K., Rich, J., Neill, M., Touzard-Romo, F., et al. (2020). Convalescent plasma for patients with severe COVID-19: a matched cohort study. Clin. Infect. Dis. 10, ciaa1548. doi:10.1093/cid/ciaa1548

Rogers, T. F., Zhao, F., Huang, D., Beutler, N., Burns, A., He, W. T., et al. (2020). Isolation of potent SARS-CoV-2 neutralizing antibodies and protection from disease in a small animal model. Science 369 (6506), 956-963. doi:10.1126/ science.abc 7520

Rojas, M., Rodríguez, Y., Monsalve, D. M., Acosta-Ampudia, Y., Camacho, B., Gallo, J. E., et al. (2020). Convalescent plasma in Covid-19: possible mechanisms of action. Autoimmun. Rev. 19, 102554. doi:10.1016/j.autrev. 2020.102554

Rosenberg, E. S., Dufort, E. M., Udo, T., Wilberschied, L. A., Kumar, J., Tesoriero, J., et al. (2020). Association of treatment with hydroxychloroquine or azithromycin with in-hospital mortality in patients with COVID-19 in New York state. Jama 323, 2493-2502. doi:10.1001/jama.2020.8630

Rossi, B., Nguyen, L. S., Zimmermann, P., Boucenna, F., Dubret, L., Baucher, L., et al. (2020). Effect of tocilizumab in hospitalized patients with severe COVID19 pneumonia: a case-control cohort study. Pharmaceuticals 13 (10), 317. doi:10.3390/ph13100317

Rossi, R., Coppi, F., Talarico, M., and Boriani, G. (2020). Protective role of chronic treatment with direct oral anticoagulants in elderly patients affected by interstitial pneumonia in COVID-19 era. Eur. J. Intern. Med. 77, 158-160. doi:10.1016/j.ejim.2020.06.006

Runfeng, L., Yunlong, H., Jicheng, H., Weiqi, P., Qinhai, M., Yongxia, S., et al. (2020). Lianhuaqingwen exerts anti-viral and anti-inflammatory activity against novel coronavirus (SARS-CoV-2). Pharmacol. Res. 156, 104761. doi:10.1016/j.phrs.2020.104761

Russell, C. D., Millar, J. E., and Baillie, J. K. (2020). Clinical evidence does not support corticosteroid treatment for 2019-nCoV lung injury. Lancet 395, 473. doi:10.1016/S0140-6736(20)30317-2

Russo, V., Di Maio, M., Attena, E., Silverio, A., Scudiero, F., Celentani, D., et al. (2020). Clinical impact of pre-admission antithrombotic therapy in hospitalized patients with COVID-19: a multicenter observational study. Pharmacol. Res. 159, 104965. doi:10.1016/j.phrs.2020.104965

Sacramento, C. Q., de Melo, G. R., de Freitas, C. S., Rocha, N., Hoelz, L. V., Miranda, M., et al. (2017). The clinically approved antiviral drug sofosbuvir inhibits Zika virus replication. Sci. Rep. 7, 40920. doi:10.1038/srep40920

Salazar, E., Perez, K. K., Ashraf, M., Chen, J., Castillo, B., Christensen, P. A., et al. (2020). Treatment of COVID-19 patients with convalescent plasma. Houston, Texas: medRxiv.

Sanchez-Guijo, F., Garcia-Arranz, M., Lopez-Parra, M., Monedero, P., MataMartinez, C., Santos, A., et al. (2020). Adipose-derived mesenchymal stromal cells for the treatment of patients with severe SARS-CoV-2 pneumonia requiring mechanical ventilation. A proof of concept study. EClinicalMed. 25, 100454. doi:10.1016/j.eclinm.2020.100454

Sanchez-Montalva, A., Selares-Nadal, J., Espinosa-Pereiro, J., Fernandez-Hidalgo, N., Perez-Hoyos, S., Salvador, F., et al. (2020). Early outcomes of tocilizumab in adults hospitalized with severe COVID19. An initial report from the Vall d'Hebron COVID19 prospective cohort study. Available at: https://www. medrxiv.org/content/10.1101/2020.05.07.20094599v1.full.

Sanders, J. M., Monogue, M. L., Jodlowski, T. Z., and Cutrell, J. B. (2020). Pharmacologic treatments for coronavirus disease 2019 (COVID-19): a review. Jama 323, 1824-1836. doi:10.1001/jama.2020.6019

Savarino, A., Lucia, M. B., Rastrelli, E., Rutella, S., Golotta, C., Morra, E., et al. (2004). Anti-HIV effects of chloroquine: inhibition of viral particle glycosylation and synergism with protease inhibitors. JAIDS 35 (3), 223-232. doi:10.1097/00126334-200403010-00002

Schmith, V. D., Zhou, J. J., and Lohmer, L. R. L. (2020). The approved dose of ivermectin alone is not the ideal dose for the treatment of COVID-19. Clin. Pharmacol. Ther. 108 (4), 762-765. doi:10.1002/cpt.1889

Schrezenmeier, E., and Dörner, T. (2020). Mechanisms of action of hydroxychloroquine and chloroquine: implications for rheumatology. Nat. Rev. Rheumatol. 16 (3), 155-166. doi:10.1038/s41584-020-0372-x

Sciascia, S., Aprà, F., Baffa, A., Baldovino, S., Boaro, D., Boero, R., et al. (2020). Pilot prospective open, single-arm multicentre study on off-label use of tocilizumab in patients with severe COVID-19. Clin. Exp. Rheumatol. 38, 529-532. 
Serviddio, G., Villani, R., Stallone, G., Scioscia, G., Foschino-Barbaro, M. P., and Lacedonia, D. (2020). Tocilizumab and liver injury in patients with COVID-19. Therap. Adv. Gastroenterol. 13, 1756284820959183. doi:10.1177/1756284820959183

Shao, Z., Feng, Y., Zhong, L., Xie, Q., Lei, M., Liu, Z., et al. (2020). Clinical efficacy of intravenous immunoglobulin therapy in critical patients with COVID-19: a multicenter retrospective cohort study. Available at: https://www.medrxiv.org/ content/10.1101/2020.04.11.20061739v2.

Sheahan, T. P., Sims, A. C., Graham, R. L., Menachery, V. D., Gralinski, L. E., Case, J. B., et al. (2017). Broad-spectrum antiviral GS-5734 inhibits both epidemic and zoonotic coronaviruses. Sci. Transl. Med. 9 (396), eaal3653. doi:10.1126/ scitranslmed.aal3653

Shen, C., Wang, Z., Zhao, F., Yang, Y., Li, J., Yuan, J., et al. (2020). Treatment of 5 critically ill patients with COVID-19 with convalescent plasma. Jama 323, 1582-1589. doi:10.1001/jama.2020.4783

Shi, H., Zhou, C., He, P., Huang, S., Duan, Y., Wang, X., et al. (2020). Successful treatment of plasma exchange followed by intravenous immunogloblin in a critically ill patient with 2019 novel coronavirus infection. Int. J. Antimicrob. Agents 56, 105974. doi:10.1016/j.ijantimicag.2020.105974

Sirimaturos, M., Gotur, D. B., Patel, S. J., Dreucean, D., Jakowenko, N., Cooper, M. H., et al. (2020). Clinical outcomes following tocilizumab administration in mechanically ventilated coronavirus disease 2019 patients. Crit. Care Explor. 2 (10), e0232. doi:10.1097/CCE.0000000000000232

Skipper, C. P., Pastick, K. A., Engen, N. W., Bangdiwala, A. S., Abassi, M., Lofgren, S. M., et al. (2020). Hydroxychloroquine in nonhospitalized adults with early COVID-19: a randomized trial. Ann. Intern. Med. 173 (8), 623-631. doi:10. 7326/m20-4207

Smieszek, S. P., Przychodzen, B. P., and Polymeropoulos, M. H. (2020). Amantadine disrupts lysosomal gene expression: a hypothesis for COVID19 treatment. Int. J. Antimicrob. Agents 55, 106004. doi:10.1016/j.ijantimicag.2020.106004

Song, X., Ji, J., Reva, B., Joshi, H., Calinawan, A. P., Mazumdar, M., et al. (2020). Post-anticoagulant D-dimer as a highly prognostic biomarker of COVID-19 mortality. Available at: https://www.medrxiv.org/content/10.1101/2020.09.02. $20180984 \mathrm{v} 1$.

Spinner, C. D., Gottlieb, R. L., Criner, G. J., Arribas López, J. R., Cattelan, A. M., Soriano Viladomiu, A., et al. (2020). Effect of remdesivir vs standard care on clinical status at 11 Days in patients with moderate COVID-19: a randomized clinical trial. Jama 324 (11), 1048-1057. doi:10.1001/jama.2020.16349

Stone, J. H., Frigault, M. J., Serling-Boyd, N. J., Fernandes, A. D., Harvey, L., Foulkes, A. S., et al. (2020). Efficacy of tocilizumab in patients hospitalized with covid-19. N. Engl. J. Med. 383, 2333-2344. doi:10.1056/NEJMoa2028836

Stower, H. (2020). Lopinavir-ritonavir in severe COVID-19. Nat. Med. 26 (4), 465. doi:10.1038/s41591-020-0849-9

Taccone, F. S., Gevenois, P. A., Peluso, L., Pletchette, Z., Lheureux, O., Brasseur, A., et al. (2020). Higher intensity thromboprophylaxis regimens and pulmonary embolism in critically ill coronavirus disease 2019 patients. Crit. Care Med. 48 (11), e1087-e1090. doi:10.1097/CCM.0000000000004548

Takoi, H., Togashi, Y., Fujimori, D., Kaizuka, H., Otsuki, S., Wada, T., et al. (2020). Favipiravir-induced fever in coronavirus disease 2019: a report of two cases. Int. J. Infect. Dis. 101, 188-190. doi:10.1016/j.ijid.2020.09.1450

Tang, L., Jiang, Y., Zhu, M., Chen, L., Zhou, X., Zhou, C., et al. (2020). Clinical study using mesenchymal stem cells for the treatment of patients with severe COVID19. Front. Med. 14 (5), 664-673. doi:10.1007/s11684-020-0810-9

Tang, N., Bai, H., Chen, X., Gong, J., Li, D., and Sun, Z. (2020a). Anticoagulant treatment is associated with decreased mortality in severe coronavirus disease 2019 patients with coagulopathy. J. Thromb. Haemostasis 18 (5), 1094-1099. doi:10.1111/jth.14817

Tang, N., Li, D., Wang, X., and Sun, Z. (2020b). Abnormal coagulation parameters are associated with poor prognosis in patients with novel coronavirus pneumonia. J. Thromb. Haemostasis 18 (4), 844-847. doi:10.1111/jth.14768

Tang, W., Cao, Z., Han, M., Wang, Z., Chen, J., Sun, W., et al. (2020). Hydroxychloroquine in patients with mainly mild to moderate coronavirus disease 2019: open label, randomised controlled trial. Br. Med. J. 369, m1849. doi:10.1136/bmj.m1849

Tchesnokov, E. P., Feng, J. Y., Porter, D. P., and Götte, M. (2019). Mechanism of inhibition of Ebola virus RNA-dependent RNA polymerase by remdesivir. Viruses 11 (4), 326. doi:10.3390/v11040326

te Velthuis, A. J., van den Worm, S. H., Sims, A. C., Baric, R. S., Snijder, E. J., and van Hemert, M. J. (2010). $\mathrm{Zn}(2+)$ inhibits coronavirus and arterivirus RNA polymerase activity in vitro and zinc ionophores block the replication of these viruses in cell culture. PLoS Pathog. 6 (11), e1001176. doi:10.1371/journal.ppat.1001176

Tian, S., Xiong, Y., Liu, H., Niu, L., Guo, J., Liao, M., et al. (2020). Pathological study of the 2019 novel coronavirus disease (COVID-19) through postmortem core biopsies. Mod. Pathol. 33, 1007-1014. doi:10.1038/s41379-020-0536-x

Tian, X., Li, C., Huang, A., Xia, S., Lu, S., Shi, Z., et al. (2020). Potent binding of 2019 novel coronavirus spike protein by a SARS coronavirus-specific human monoclonal antibody. Emerg. Microb. Infect. 9 (1), 382-385. doi:10.1080/ 22221751.2020.1729069

Toniati, P., Piva, S., Cattalini, M., Garrafa, E., Regola, F., Castelli, F., et al. (2020). Tocilizumab for the treatment of severe COVID-19 pneumonia with hyperinflammatory syndrome and acute respiratory failure: a single center study of 100 patients in Brescia, Italy. Autoimmun. Rev. 19, 102568. doi:10. 1016/j.autrev.2020.102568

Totura, A. L., and Baric, R. S. (2012). SARS coronavirus pathogenesis: host innate immune responses and viral antagonism of interferon. Curr. Opin. Virol. 2 (3), 264-275. doi:10.1016/j.coviro.2012.04.004

Trinh, M., Chang, D. R., Govindarajulu, U. S., Kane, E., Fuster, V., Kohli-Seth, R., et al. (2020). Therapeutic anticoagulation is associated with decreased mortality in mechanically ventilated COVID-19 patients. Available at: https://www. medrxiv.org/content/10.1101/2020.05.30.20117929v1.

Tursi, A., Vetrone, L. M., and Papa, A. (2020). Anti-TNF- $a$ agents in inflammatory bowel disease and course of COVID-19. Inflamm. Bowel Dis. 26, e73. doi:10. 1093/ibd/izaa114

Vankadari, N. (2020). Arbidol: a potential antiviral drug for the treatment of SARSCoV-2 by blocking trimerization of the spike glycoprotein. Int. J. Antimicrob. Agents 56, 105998. doi:10.1016/j.ijantimicag.2020.105998

Vásárhelyi, B., Sátori, A., Olajos, F., Szabó, A., and Beko, G. (2011). Alacsony D-vitamin-szint a Semmelweis Egyetem betegei körében: a központi laboratóriumban egy év alatt meghatározott D-vitamin-szintek retrospektív értékelése. Available at: https://core.ac.uk/download/pdf/83096803.pdf.

Viecca, M., Radovanovic, D., Forleo, G. B., and Santus, P. (2020). Enhanced platelet inhibition treatment improves hypoxemia in patients with severe Covid-19 and hypercoagulability. A case control, proof of concept study. Pharmacol. Res. 158, 104950. doi:10.1016/j.phrs.2020.104950

Vinetz, J. M. (2020). Lack of efficacy of hydroxychloroquine in covid-19. Br. Med. J. 369, m2018. doi:10.1136/bmj.m2018

Virtanen, T., Haikarainen, T., Raivola, J., and Silvennoinen, O. (2019). Selective JAKinibs: prospects in inflammatory and autoimmune diseases. BioDrugs 33 (1), 15-32. doi:10.1007/s40259-019-00333-w

Volk, A., Hackbart, M., Deng, X., Cruz-Pulido, Y., O'Brien, A., and Baker, S. C. (2020). Coronavirus endoribonuclease and deubiquitinating interferon antagonists differentially modulate the host response during replication in macrophages. J. Virol. 11, e00178. doi:10.1128/JVI.00178-20

Wadud, N., Ahmed, N., Mannu Shergil, M., Khan, M., Krishna, M. G., Gilani, A., et al. (2020). Improved survival outcome in SARs-CoV-2 (COVID-19) acute respiratory distress syndrome patients with tocilizumab administration. Available at: https:// www.medrxiv.org/content/10.1101/2020.05.13.20100081v1.full.pdf.

Wagstaff, K. M., Sivakumaran, H., Heaton, S. M., Harrich, D., and Jans, D. A. (2012). Ivermectin is a specific inhibitor of importin alpha/beta-mediated nuclear import able to inhibit replication of HIV-1 and dengue virus. Biochem. J. 443 (3), 851-856. doi:10.1042/bj20120150

Wan, J., Xing, S., Ding, L., Wang, Y., Gu, C., Wu, Y., et al. (2020). Human-IgGneutralizing monoclonal antibodies block the SARS-CoV-2 infection. Cell Rep. 32 (3), 107918. doi:10.1016/j.celrep.2020.107918

Wan, Y., Shang, J., Graham, R., Baric, R. S., and Li, F. (2020). Receptor recognition by the novel coronavirus from wuhan: an analysis based on decade-long structural studies of SARS coronavirus. J. Virol. 94 (7), 20. doi:10.1128/jvi.00127-20

Wang, D., Hu, B., Hu, C., Zhu, F., Liu, X., Zhang, J., et al. (2020). Clinical characteristics of 138 hospitalized patients with 2019 novel coronavirusinfected pneumonia in wuhan, China. Jama 323 (11), 1061-1069. doi:10. 1001/jama.2020.1585

Wang, J. (2020). First application of thalidomide for COVID-19 suggested effective in first affiliated hospital of Wenzhou medical university. Available at: http://zj. news.163.com/20/0219/17/F5OV8H6F04098FEB.html.

Wang, M., Cao, R., Zhang, L., Yang, X., Liu, J., Xu, M., et al. (2020). Remdesivir and chloroquine effectively inhibit the recently emerged novel coronavirus (2019$\mathrm{nCoV}$ ) in vitro. Cell Res. 30 (3), 269-271. doi:10.1038/s41422-020-0282-0 
Wang, Q., Zhang, Y., Wu, L., Niu, S., Song, C., Zhang, Z., et al. (2020). Structural and functional basis of SARS-CoV-2 entry by using human ACE2. Cell 181 (4), 894-904. doi:10.1016/j.cell.2020.03.045

Wang, X., Cao, R., Zhang, H., Liu, J., Xu, M., Hu, H., et al. (2020). The antiinfluenza virus drug, arbidol is an efficient inhibitor of SARS-CoV-2 in vitro. Cell Discov. 6, 28. doi:10.1038/s41421-020-0169-8

Wang, Y., Zhang, D., Du, G., Du, R., Zhao, J., Jin, Y., et al. (2020). Remdesivir in adults with severe COVID-19: a randomised, double-blind, placebo-controlled, multicentre trial. Lancet 395 (10236), 1569-1578. doi:10.1016/s0140-6736(20)31022-9

Wang, Z., Chen, X., Lu, Y., Chen, F., and Zhang, W. (2020). Clinical characteristics and therapeutic procedure for four cases with 2019 novel coronavirus pneumonia receiving combined Chinese and Western medicine treatment. BioScience Trends 14 (1), 64-68. doi:10.5582/bst.2020.01030

Warren, T. K., Jordan, R., Lo, M. K., Ray, A. S., Mackman, R. L., Soloveva, V., et al. (2016). Therapeutic efficacy of the small molecule GS-5734 against Ebola virus in rhesus monkeys. Nature 531 (7594), 381-385. doi:10.1038/nature17180

Warren, T. K., Wells, J., Panchal, R. G., Stuthman, K. S., Garza, N. L., Van Tongeren, S. A., et al. (2014). Protection against filovirus diseases by a novel broad-spectrum nucleoside analogue BCX4430. Nature 508 (7496), 402-405. doi:10.1038/nature13027

Westover, J. B., Mathis, A., Taylor, R., Wandersee, L., Bailey, K. W., Sefing, E. J., et al. (2018). Galidesivir limits Rift Valley fever virus infection and disease in Syrian golden hamsters. Antivir. Res. 156, 38-45. doi:10.1016/j.antiviral.2018.05.013

Winkler, A. M., and Koepsell, S. A. (2015). The use of convalescent plasma to treat emerging infectious diseases: focus on Ebola virus disease. Curr. Opin. Hematol. 22 (6), 521-526. doi:10.1097/MOH.0000000000000191

Wrapp, D., Wang, N., Corbett, K. S., Goldsmith, J. A., Hsieh, C.-L., Abiona, O., et al. (2020). Cryo-EM structure of the 2019-nCoV spike in the prefusion conformation. Science 367 (6483), 1260-1263. doi:10.1126/science.abb2507

Wu, C., Chen, X., Cai, Y., Xia, J., Zhou, X., Xu, S., et al. (2020). Risk factors associated with acute respiratory distress syndrome and death in patients with coronavirus disease 2019 pneumonia in Wuhan, China. JAMA Intern Med. 180, 934-943. doi:10.1001/jamainternmed.2020.0994

Wu, J., Huang, J., Zhu, G., Liu, Y., Xiao, H., Zhou, Q., et al. (2020). Systemic corticosteroids show no benefit in severe and critical COVID-19 patients in Wuhan, China: a retrospective cohort study. Available at: https://www.medrxiv. org/content/10.1101/2020.05.11.20097709v1.

Wu, T., Zuo, Z., Kang, S., Jiang, L., Luo, X., Xia, Z., et al. (2020). Multi-organ dysfunction in patients with COVID-19: a systematic review and meta-analysis. Aging Dis. 11 (4), 874-894. doi:10.14336/AD.2020.0520

Xu, X., Han, M., Li, T., Sun, W., Wang, D., Fu, B., et al. (2020). Effective treatment of severe COVID-19 patients with tocilizumab. Proc. Natl. Acad. Sci. U. S. A. 117, 10970-10975. doi:10.1073/pnas.2005615117

Xu, Z., Shi, L., Wang, Y., Zhang, J., Huang, L., Zhang, C., et al. (2020). Pathological findings of COVID-19 associated with acute respiratory distress syndrome. Lancet Respir. Med. 8 (4), 420-422. doi:10.1016/s2213-2600(20)30076-x

Yamamoto, N., Yang, R., Yoshinaka, Y., Amari, S., Nakano, T., Cinatl, J., et al. (2004). HIV protease inhibitor nelfinavir inhibits replication of SARSassociated coronavirus. Biochem. Biophys. Res. Commun. 318 (3), 719-725. doi:10.1016/j.bbrc.2004.04.083

Yan, D., Liu, X.-Y., Zhu, Y.-N., Huang, L., Dan, B.-T., Zhang, G.-J., et al. (2020). Factors associated with prolonged viral shedding and impact of Lopinavir/ Ritonavir treatment in patients with SARS-CoV-2 infection. Eur. Respir. J. 56, 2000799. doi:10.1183/13993003.00799-2020

Yang, J., Zheng, Y., Gou, X., Pu, K., Chen, Z., Guo, Q., et al. (2020). Prevalence of comorbidities and its effects in coronavirus disease 2019 patients: a systematic review and meta-analysis. Int. J. Infect. Dis. 94, 91-95. doi:10.1016/j.ijid.2020.03.017

Yang, N., and Shen, H. M. (2020). Targeting the endocytic pathway and autophagy process as a novel therapeutic strategy in COVID-19. Int. J. Biol. Sci. 16 (10), 1724-1731. doi:10.7150/ijbs.45498

Yang, Z., Liu, J., Zhou, Y., Zhao, X., Zhao, Q., and Liu, J. (2020). The effect of corticosteroid treatment on patients with coronavirus infection: a systematic review and meta-analysis. J. Infect. 81, e13-e20. doi:10.1016/j.jinf.2020.03.062

Yao, L. M., Xin, Li., Huang, J., and Cao, H. (2020). Retrospective clinical analysis on treatment of coronavirus disease 2019 with traditional Chinese medicine lianhua qingwen. Chin. J. Exp. Trad. Med. For. 18, 206-210. doi:10.13422/j.cnki.syfjx.20201099

Ye, M., Fu, D., Ren, Y., Wang, F., Wang, D., Zhang, F., et al. (2020). Treatment with convalescent plasma for COVID-19 patients in Wuhan, China. J. Med. Virol. 92, 1890-1901. doi:10.1002/jmv.25882
Ye, X. T., Luo, Y. L., Xia, S. C., Sun, Q. F., Ding, J. G., Zhou, Y., et al. (2020). Clinical efficacy of lopinavir/ritonavir in the treatment of Coronavirus disease 2019. Eur. Rev. Med. Pharmacol. Sci. 24 (6), 3390-3396. doi:10.26355/ eurrev_202003_20706

Yi, C. D. L. (2020). Clinical effectiveness and case analysis in 54 NCP patients treated with lanhuaqingwen granules. World Chin. Med. 15 (2), 150-154.

Young, B. E., Ong, S. W. X., Kalimuddin, S., Low, J. G., Tan, S. Y., Loh, J., et al. (2020). Epidemiologic features and clinical course of patients infected with SARS-CoV-2 in Singapore. Jama 323, 1488-1494. doi:10.1001/jama.2020.3204

Yuen, C. K., Lam, J. Y., Wong, W. M., Mak, L. F., Wang, X., Chu, H., et al. (2020). SARS-CoV-2 nsp13, nsp14, nsp15 and orf6 function as potent interferon antagonists. Emerg. Microb. Infect. 9 (1), 1418-1428. doi:10.1080/22221751. 2020.1780953

Zeng, Q. L., Yu, Z. J., Gou, J. J., Li, G. M., Ma, S. H., Zhang, G. F., et al. (2020). Effect of convalescent plasma therapy on viral shedding and survival in patients with coronavirus disease 2019. J. Infect. Dis. 222 (1), 38-43. doi:10.1093/infdis/jiaa228

Zhang, C., Wang, W., and Jiang, X. (2020). Clinical observation of xuebijing in treating new coronavirus pneumonia. Available at: http://kns.cnki.net $/ \mathrm{kcms} /$ detail/42.1204.r.20200409.1637.002.html.

Zhang, H., Penninger, J. M., Li, Y., Zhong, N., and Slutsky, A. S. (2020). Angiotensin-converting enzyme 2 (ACE2) as a SARS-CoV-2 receptor: molecular mechanisms and potential therapeutic target. Intensive Care Med. 46 (4), 586-590. doi:10.1007/s00134-020-05985-9

Zhang, J., Yao, Q., and Liu, Z. (2015). An effective synthesis method for tilorone dihydrochloride with obvious IFN- $\alpha$ inducing activity. Molecules 20 (12), 21458-21463. doi:10.3390/molecules201219781

Zhang, X., Xue, Y., Chen, X., Wu, J. M., Su, Z. J., Sun, M., et al. (2020). Effects of Tanreqing Capsule on the negative conversion time of nucleic acid in patients with COVID-19: a retrospective cohort study. J Integr. Med. S2095-4964 (20), 30108-30114. doi:10.1016/j.joim.2020.10.002

Zhao, Q., Ahmed, M., Guo, H. F., Cheung, I. Y., and Cheung, N. K. (2015a). Alteration of electrostatic surface potential enhances affinity and tumor killing properties of anti-ganglioside GD2 monoclonal antibody hu3F8. J. Biol. Chem. 290 (21), 13017-13027. doi:10.1074/jbc.M115.650903

Zhao, Q., Ahmed, M., Tassev, D. V., Hasan, A., Kuo, T. Y., Guo, H. F., et al. (2015b). Affinity maturation of T-cell receptor-like antibodies for Wilms tumor 1 peptide greatly enhances therapeutic potential. Leukemia 29 (11), 2238-2247. doi:10.1038/leu.2015.125

Zhou, F., Yu, T., Du, R., Fan, G., Liu, Y., Liu, Z., et al. (2020). Clinical course and risk factors for mortality of adult inpatients with COVID-19 in Wuhan, China: a retrospective cohort study. Lancet 395 (10229), 1054-1062. doi:10.1016/ s0140-6736(20)30566-3

Zhou, P., Yang, X. L., Wang, X. G., Hu, B., Zhang, L., Zhang, W., et al. (2020). A pneumonia outbreak associated with a new coronavirus of probable bat origin. Nature 579 (7798), 270-273. doi:10.1038/s41586-020-2012-7

Zhou, Z., Zhu, C. S., and Zhang, B. (2020). Study on medication regularity of traditional Chinese medicine in treatment of COVID-19 based on data mining. Zhongguo Zhong Yao Za Zhi 45, 1248-1252. doi:10.19540/j.cnki.cjcmm.20200220.502

Zhu, Z., Lu, Z., Xu, T., Chen, C., Yang, G., Zha, T., et al. (2020). Arbidol monotherapy is superior to lopinavir/ritonavir in treating COVID-19. J. Infect. 81, e21-e23. doi:10.1016/j.jinf.2020.03.060

Zumla, A., Hui, D. S., and Perlman, S. (2015). Middle East respiratory syndrome. Lancet 386 (9997), 995-1007. doi:10.1016/S0140-6736(15)60454-8

Conflict of Interest: Author XL was employed by Hunan Yuanpin Cell Biotechnology Co., Ltd.

The remaining authors declare that the research was conducted in the absence of any commercial or financial relationships that could be construed as a potential conflict of interest.

Copyright (c) $2021 \mathrm{Zuo}, W u$, Pan, Zuo, Hu, Luo, Jiang, Xia, Xiao, Liu, Ye and Deng. This is an open-access article distributed under the terms of the Creative Commons Attribution License (CC BY). The use, distribution or reproduction in other forums is permitted, provided the original author(s) and the copyright owner $(s)$ are credited and that the original publication in this journal is cited, in accordance with accepted academic practice. No use, distribution or reproduction is permitted which does not comply with these terms. 